\title{
Importance de mieux connaître les mécanismes de transport des métaux pour la prédiction de l'accumulation et de la toxicité des métaux dissous chez le phytoplancton : récentes avancées et défis pour le développement du modèle du ligand biotique
}

\section{The importance of gathering more knowledge on metal transport mechanisms to predict the uptake and toxicity of dissolved metals by phytoplankton: new insights and challenges for the development of the biotic ligand model}

\author{
Michel Lavoie, Peter G.C. Campbell et Claude Fortin
}

Volume 29, numéro 2, 2016

Reçu le 19 octobre 2015, accepté le 9 février 2016

URI : https://id.erudit.org/iderudit/1036544ar

DOI : https://doi.org/10.7202/1036544ar

Aller au sommaire du numéro

Éditeur(s)

Université du Québec - INRS-Eau, Terre et Environnement (INRS-ETE)

ISSN

1718-8598 (numérique)

Découvrir la revue

Citer cet article

Lavoie, M., Campbell, P. G. \& Fortin, C. (2016). Importance de mieux connaître les mécanismes de transport des métaux pour la prédiction de l'accumulation et de la toxicité des métaux dissous chez le phytoplancton : récentes avancées et défis pour le développement du modèle du ligand biotique. Revue des sciences de l'eau / Journal of Water Science, 29(2), 119-147. https://doi.org/10.7202/1036544ar
Résumé de l'article

L'accumulation et la toxicité (aigüe) des métaux dissous chez plusieurs organismes aquatiques peuvent être prédites adéquatement à l'aide du modèle du ligand biotique (MLB), même si quelques exceptions existent. Lors d'expositions chroniques aux métaux, des interactions physiologiques complexes entre les organismes et les métaux essentiels et non essentiels modulent le taux de transport des métaux et leur toxicité. La présente revue de littérature aborde les récentes avancées en chimie de l'environnement, en biologie moléculaire et en physiologie cellulaire touchant aux mécanismes de régulation du transport membranaire des métaux essentiels chez le phytoplancton eucaryote et leurs impacts sur l'accumulation et la toxicité d'un métal habituellement non essentiel, le cadmium. Cette revue évalue finalement la possibilité d'inclure des éléments de physiologie algale dans la présente version du MLB afin d'améliorer le potentiel de ce modèle à prédire l'accumulation et la toxicité des métaux pour des expositions chroniques. Les résultats disponibles dans la littérature suggèrent que l'inclusion des rétroactions négatives et positives des métaux sur les paramètres cinétiques $\left(V_{\max }\right.$ : vitesse maximale de transport transmembranaire; $K_{M}$ : affinité des transporteurs pour le métal) des multiples systèmes de transport membranaire des métaux a le potentiel d'améliorer les prédictions de l'accumulation et de la toxicité des métaux à long terme chez le phytoplancton. Le développement d'un MLB capable de prédire adéquatement la toxicité chronique des métaux dans des conditions physicochimiques variables représentatives de celles retrouvées en milieu naturel bénéficiera des avancées récentes et futures en toxicologie, biologie et chimie de l'environnement. Ces connaissances pourraient permettre à long terme d'atteindre l'objectif ambitieux d'un MLB capable de réaliser des prédictions fiables à l'intérieur de milieux naturels complexes de différentes compositions chimiques. 


\section{IMPORTANCE DE MIEUX CONNAÎTRE LES MÉCANISMES DE TRANSPORT DES MÉTAUX POUR LA PRÉDICTION DE L'ACCUMULATION ET DE LA TOXICITÉ DES MÉTAUX DISSOUS CHEZ LE PHYTOPLANCTON : RÉCENTES AVANCÉES ET DÉFIS POUR LE DÉVELOPPEMENT DU MODĖLE DU LIGAND BIOTIQUE}

The importance of gathering more knowledge on metal transport mechanisms to predict the uptake and toxicity of dissolved metals by phytoplankton: new insights and challenges for the development of the biotic ligand model

Michel LAVOIE" ${ }^{1 *}$, PETER G.C. CAMPBELL², CLAUDE FORTIN ${ }^{2}$

${ }^{1}$ Québec-Océan et Unité Mixte Internationale Takuvik Université Laval-CNRS, Département de Biologie, Université Laval, Québec (Québec) G1K 7P4, Canada

${ }^{2}$ Centre Eau Terre Environnement, Institut national de la recherche scientifique, 490 rue de la Couronne, Québec (Québec) G1K 9A9, Canada

Reçu le 19 octobre 2015, accepté le 9 février 2016

\section{RÉSUMÉ}

L'accumulation et la toxicité (aigüe) des métaux dissous chez plusieurs organismes aquatiques peuvent être prédites adéquatement à l'aide du modèle du ligand biotique (MLB), même si quelques exceptions existent. Lors d'expositions chroniques aux métaux, des interactions physiologiques complexes entre les organismes et les métaux essentiels et non essentiels modulent le taux de transport des métaux et leur toxicité. La présente revue de littérature aborde les récentes avancées en chimie de l'environnement, en biologie moléculaire et en physiologie cellulaire touchant aux mécanismes de régulation du transport membranaire des métaux essentiels chez le phytoplancton eucaryote et leurs impacts sur l'accumulation et la toxicité d'un métal habituellement non essentiel, le cadmium. Cette revue évalue finalement la possibilité d'inclure des éléments de physiologie algale dans la présente version du MLB afin d'améliorer le potentiel de ce modèle à prédire l'accumulation et la toxicité des métaux pour des expositions chroniques. Les résultats disponibles dans la littérature suggèrent que l'inclusion des rétroactions négatives et positives des métaux sur les paramètres cinétiques $\left(V_{\max }\right.$ : vitesse maximale de transport transmembranaire; $K_{M}$ : affinité des transporteurs pour le métal) des multiples systèmes de transport membranaire des métaux a le potentiel d'améliorer les prédictions de l'accumulation et de la toxicité des métaux à long terme chez le phytoplancton. Le développement d'un MLB capable de prédire adéquatement la toxicité chronique 
des métaux dans des conditions physicochimiques variables représentatives de celles retrouvées en milieu naturel bénéficiera des avancées récentes et futures en toxicologie, biologie et chimie de l'environnement. Ces connaissances pourraient permettre à long terme d'atteindre l'objectif ambitieux d'un MLB capable de réaliser des prédictions fiables à l'intérieur de milieux naturels complexes de différentes compositions chimiques.

Mots-clés : Modèle du ligand biotique, toxicité des métaux, phytoplancton, physiologie algale, transport membranaire des métaux.

\section{ABSTRACT}

The accumulation and (acute) toxicity of dissolved metals in many aquatic organisms are normally well predicted with the biotic ligand model (BLM), although some exceptions have been reported. In long-term chronic metal exposures, complex physiological interactions with essential and nonessential metals may modulate metal uptake rates and toxicity. The present literature review discusses recent advances in environmental chemistry, molecular biology, and physiology related to the regulatory mechanisms of membrane transport of essential metals in eukaryotic phytoplankton and to their impacts on the accumulation and toxicity of cadmium, a usually non-essential metal. This literature review finally evaluates the possibility of including elements of algal physiology in the current version of the BLM in order to enhance the potential of this model to predict metal uptake and toxicity in chronic exposures. The available results in the literature suggest that the inclusion of negative and positive feedback interactions of metals on the kinetic parameters $\left(V_{\text {max }}\right.$ : maximal uptake rate; $K_{M}$ : metal affinity of the transport sites) of multiple metal transport systems shows promise for better predicting the longterm accumulation and toxicity of metals in phytoplankton. The development of a BLM able to predict the chronic toxicity of metals under various physicochemical conditions representative of those found in the environment will benefit from recent and future advances in toxicology, biology and environmental chemistry. The knowledge gained will aid in achieving the ambitious goal of developing an extended BLM that reliably predicts metal toxicity in complex natural aquatic environments.

Key Words: Biotic ligand model, metal toxicity, phytoplankton, algal physiology, metal transport systems.

\section{INTRODUCTION: LES MÉTAUX TRACES DANS L'ENVIRONNEMENT ET LEURS RÔLES DANS LE MÉTABOLISME ET L'ÉVOLUTION DU PHYTOPLANCTON}

Les métaux traces sont naturellement présents dans la croûte terrestre et dans les milieux aquatiques. Leurs abondances relatives particulières résultent du Big Bang et d'événements astronomiques subséquents. Au tout début de la vie sur Terre, soit vers l'apparition des premières cellules procaryotes primitives, il y a plus de $3,5 \cdot 10^{9}$ années, les métaux traces les plus abondants et disponibles sous forme soluble (B, Co, Fe, Mn, Mo, Ni, W et, dans une moindre mesure : $\mathrm{Cu}$ et $\mathrm{Zn}$ ) auraient été sélectionnés par les premières cellules vivantes comme oligo-éléments constitutifs essentiels du métabolisme. D'autres métaux possédant souvent un poids atomique plus élevé (ex. : $\mathrm{Ag}, \mathrm{Cd}, \mathrm{Hg}, \mathrm{Pb}, \mathrm{Pd}$ et $\mathrm{Po}$ ) n'auraient habituellement pas été sélectionnés comme métaux de choix pour subvenir aux besoins métaboliques des cellules vivantes (SAITO et al., 2003; WILLIAMS, 2002). L'évolution a fait en sorte de sélectionner peu à peu les organismes ayant développé des mécanismes homéostatiques efficaces permettant de réguler les concentrations intracellulaires des métaux essentiels à l'intérieur d'une gamme optimale et d'exclure ou de détoxiquer les métaux non essentiels.

Les " véritables usines chimiques " (de là, on désigne les organismes aquatiques de notre époque!) créées par le " moteur " de l'évolution interagissent de façon complexe avec les métaux présents dans le milieu faisant en sorte que la prise en charge et la toxicité des métaux sont relativement complexes à modéliser. Toutefois, des modèles perfectionnés permettant de prédire la prise en charge et la toxicité (aigüe) des métaux en milieu aquatique ont été développés avec succès par les écotoxicologistes dans certaines conditions contrôlées au laboratoire. Ces modèles évoluent au fil des années afin d'étendre la portée de leurs prédictions à des conditions plus complexes et donc plus représentatives de l'environnement (PAQUIN et al., 2002a, 2002b). Cette revue de littérature présente l'état des connaissances actuelles quant au développement d'un modèle prometteur, soit le modèle du ligand biotique (MLB), pour prédire la toxicité des métaux dissous dans les écosystèmes aquatiques d'eau douce. La présente revue donne suite aux revues de littérature du MLB publiées par CAMPBELL et al. (2002) et SLAVEYKOVA et WILKINSON (2005). Elle met l'accent sur les récentes avancées scientifiques concernant les mécanismes physiologiques de transport des métaux essentiels chez des organismes unicellulaires simples, le phytoplancton eucaryote, et l'intégration de ces mécanismes au MLB. Notez que certaines études portant sur les mécanismes de transport des métaux chez le phytoplancton marin sont occasionnellement présentées pour compléter nos connaissances relativement 
sommaires des mécanismes de transport des métaux chez le phytoplancton d'eau douce. Pour une discussion exhaustive des interactions entre les métaux traces et le phytoplancton marin, le lecteur peut consulter la revue de littérature récente de SUNDA (2012).

La présente revue de littérature est divisée en quatre sections. La spéciation de cinq métaux essentiels ( $\mathrm{Co}, \mathrm{Cu}, \mathrm{Fe}, \mathrm{Mn}, \mathrm{Zn}$ ) dans les écosystèmes d'eau douce est abordée dans la première section. Dans la seconde, les mécanismes de transport des métaux essentiels en relation avec leur spéciation sont discutés. À la troisième, les prémisses et limites du MLB sont traitées. La quatrième section expose l'importance d'inclure des éléments de physiologie algale au MLB pour mieux prédire l'accumulation et la toxicité chronique des métaux. Finalement, le cas du Cd, un métal habituellement considéré comme non essentiel chez le phytoplancton eucaryote vivant en eau douce (TWISS et al., 2005), est utilisé à titre d'exemple dans la cinquième section.

\section{PRÉSENCE ET SPÉCIATION DES MÉTAUX ESSENTIELS DANS L'ENVIRON- NEMENT}

Les métaux essentiels nécessaires à la croissance du phytoplancton sont habituellement présents à l'état de trace dans l'environnement (concentrations totales habituellement de l'ordre du $\mu \mathrm{g} \cdot \mathrm{L}^{-1}$ ou nmol. $\left.\mathrm{L}^{-1}\right)$. Ils possèdent des caractéristiques chimiques qui déterminent leur spéciation en milieu aquatique. Cette section résume nos connaissances quant à la présence et la spéciation de cinq métaux essentiels ( $\mathrm{Co}, \mathrm{Cu}, \mathrm{Fe}, \mathrm{Mn}$ et $\mathrm{Zn}$ ) dans les écosystèmes d'eau douce. Pour une discussion plus complète de la spéciation des métaux dans les écosystèmes d'eau douce, le lecteur est référé à la revue de littérature récente de TERCIER-WAEBER et al. (2012). Notons que la notation de l'ion libre et du métal total privilégiée dans cette revue de littérature est celle communément utilisée en chimie de l'environnement. Le métal libre est noté $\mathrm{Me}^{2+}\left(\mathrm{ex} .: \mathrm{Cu}^{2+}\right)$ tandis que les références au métal total dissous englobant toutes les formes chimiques possibles du métal se font en utilisant le symbole chimique du métal $\mathrm{M}$ sans la charge en exposant (ex. : $\mathrm{Cu})$.

\subsection{Présence et spéciation du cobalt}

Le Co ionique comporte deux états d'oxydation, le Co(II) et le $\mathrm{Co}$ (III). Le Co(II) serait la forme majeure de la fraction dissoute, mais tendrait à former le $\mathrm{Co}(\mathrm{III})$, très peu soluble, étant la forme stable thermodynamiquement dans les eaux oxygénées. Le Co(II) et le Co(III) font partie des métaux de transition et possèdent donc un comportement chimique intermédiaire entre les métaux de classes A et B (STUMM et MORGAN, 1996). Peu de données existent au sujet de la spéciation du Co dans les eaux douces. Le $\mathrm{Co}$ (II) se comporterait un peu de la même façon que le $\mathrm{Mn}(\mathrm{II})$ pour ce qui est des processus d'oxydation qui leur sont associés. En effet, le $\mathrm{Co}$ (II) s'oxyderait en $\mathrm{Co}$ (III) plutôt lentement en eau douce en absence de catalyseur. De plus, cette réaction d'oxydation pourrait être accélérée par la présence de bactéries, quoiqu'à un taux plus faible que celui du Mn (LEE et TEBO, 1994; MOFFETT et HO, 1996; TEBO, 1998). Chez une espèce bactérienne, il a été montré que cette réaction d'oxydation n'était réalisée qu'en présence de $\mathrm{Mn}$, suggérant que l'oxydation du Co(II) ne serait qu'autocatalysée par la présence d'oxydes de Mn (MURRAY et al., 2007). Le Co(III) pourrait ensuite être réduit en Co(II) par des molécules organiques réductrices et peut-être aussi par des processus de photo-réduction. La concentration de $\mathrm{Co}(\mathrm{II})$ dissous sera fonction de l'ensemble de ces réactions d'oxydoréduction. Le Co(II) serait présent, en bonne proportion, sous sa forme libre dans les eaux douces oligotrophes du Bouclier canadien. En effet, les concentrations de $\mathrm{Co}^{2+}$ modélisées seraient de l'ordre de $10^{-11}$ à $10^{-9} \mathrm{M}$ et représenteraient plus de $60 \%$ de la concentration de Co total dissous pour un ensemble de lacs à Rouyn-Noranda et Sudbury de pH près de 7 (K. MUELLER, communication personnelle). De plus, la proportion de Co total sous forme libre mesurée dans la rivière Athabasca (Alberta, Canada) serait aussi élevée (56 à $87 \%$ du Co total sous forme libre) (CRÉMAZY et al., 2015). Toutefois, les concentrations libres de $\mathrm{Co}^{2+}$ mesurées dans différents lacs et rivières en Suisse ne représentaient généralement que $<20 \%$ du Co total dissous et variaient de $5 \cdot 10^{-11}$ à $5 \cdot 10^{-10} \mathrm{M} \mathrm{Co}^{2+}$ (QIAN et al., 1998).

\subsection{Présence et spéciation du cuivre}

Le Cu ionique possède deux états d'oxydation. Dans les eaux oxygénées, le $\mathrm{Cu}$ (II) est la forme stable thermodynamiquement tandis que le $\mathrm{Cu}(\mathrm{I})$ est instable et tend à être converti rapidement en $\mathrm{Cu}(\mathrm{II})$. Ces deux états d'oxydation sont caractérisés par une cinétique de complexation rapide aux ligands inorganiques ou organiques (constante d'échange de molécules d'eau élevée). Le $\mathrm{Cu}(\mathrm{II})$ est un métal de transition (intermédiaire entre les cations de classes $\mathrm{A}$ et $\mathrm{B}$ ) tandis que le $\mathrm{Cu}(\mathrm{I})$ est un cation de classe B, facilement polarisable (STUMM et MORGAN, 1996).

Les deux états d'oxydation interagissent avec les ligands inorganiques et organiques de façon très différente. En fait, les métaux possédant les états d'oxydation plus faibles tendent généralement à former des complexes moins stables que ceux caractérisés par des états d'oxydation plus élevés. Cependant, le $\mathrm{Cu}$ est particulier à cet égard puisque sa tendance à former des complexes avec certains ligands organiques ou inorganiques est beaucoup plus élevée sous sa forme réduite 
qu'oxydée (LEAL et VAN DEN BERG, 1998). Le Cu(I) produit par les agents réducteurs ainsi que par les mécanismes de photoréduction aura donc tendance à être stabilisé en formant des complexes relativement stables avec des molécules organiques contenant des groupements thiols si celles-ci sont présentes en concentration suffisante, par exemple dans les lacs très productifs. Dans certaines conditions, nous pouvons donc spéculer qu'une faible proportion du Cu pourrait être présente à l'état stationnaire sous forme de $\mathrm{Cu}(\mathrm{I})$ (complexé à la matière organique dissoute $[\mathrm{MOD}]$ ) lorsque le taux de réduction dépasserait le taux d'oxydation. Ce taux d'oxydation du $\mathrm{Cu}(\mathrm{I})$ en $\mathrm{Cu}(\mathrm{II})$ dépendrait de la pression partielle d'oxygène, de la température, du $\mathrm{pH}$ et surtout de la concentration de ligands pouvant former des complexes particulièrement stables avec le $\mathrm{Cu}(\mathrm{I})$. En général, le $\mathrm{Cu}(\mathrm{II})$ devrait malgré tout être l'état d'oxydation dominant dans les eaux oxygénées (LEAL et VAN DEN BERG, 1998; SHARMA et MILLERO, 1988). Le $\mathrm{Cu}(\mathrm{II})$ possède une forte tendance à s'associer aux ions hydroxyles (à des $\mathrm{pH}>6,5$ ) ainsi qu'à la MOD. Le $\mathrm{Cu}(\mathrm{I}) \mathrm{a}$, quant à lui, davantage tendance à se complexer aux thiols et aux ions chlorures.

Le Cu est présent en faible proportion et concentration sous sa forme libre dans les eaux douces naturelles. Elles pourraient atteindre $10^{-15}$ à $10^{-16} \mathrm{M} \mathrm{Cu}^{2+}$ dans les lacs eutrophes en période estivale, ce qui serait fortement relié à la productivité biologique des lacs (XUE et al., 1996; XUE et SIGG, 1993). Dans plusieurs rivières ou lacs oligotrophes non contaminés en Suisse ou sur le Bouclier canadien, les concentrations de $\mathrm{Cu}^{2+}$ libre seraient plutôt de l'ordre de $10^{-11}$ à $10^{-9} \mathrm{M}$ (FORTIN et al., 2010; KALIS et al., 2006; MUELLER et al., 2012; SIGG et al., 2006b; XUE et SUNDA, 1997). En général, dans ces différents écosystèmes oligotrophes ou eutrophes à $\mathrm{pH}$ près de la neutralité, le $\mathrm{Cu}$ est complexé à plus de $99 \%$ à la MOD faisant en sorte qu'une infime proportion du $\mathrm{Cu}$ total est sous forme de $\mathrm{Cu}^{2+}$.

\subsection{Présence et spéciation du fer}

Le Fe, quatrième élément le plus abondant dans la croûte terrestre, est paradoxalement l'élément essentiel présent en plus faible concentration sous forme libre dans les eaux oxygénées. Cette situation est causée par la très faible solubilité de ce métal en milieu oxique. En fait, le $\mathrm{Fe}$ ionique possède deux états d'oxydation, soit le Fe(III) et le Fe(II). En milieu oxygéné, il sera présent principalement sous la forme $\mathrm{Fe}(\mathrm{III})$ tandis qu'en milieu anoxique la forme $\mathrm{Fe}(\mathrm{II})$ dominera. Le $\mathrm{Fe}(\mathrm{II})$ peut cependant atteindre des concentrations non négligeables dans les eaux de surface de par la photo-réduction ou la réduction du $\mathrm{Fe}(\mathrm{III})$ par les espèces d'oxygène réactives comme l'anion superoxyde $\left(\mathrm{O}_{2}^{-}\right)$ou le peroxyde $\left(\mathrm{H}_{2} \mathrm{O}_{2}\right)$ (BUDAC et WAN, 1992; MOREL, 2008). Par la suite, le Fe(II) aura tendance à se réoxyder en $\mathrm{Fe}(\mathrm{III})$ à un rythme intimement lié au $\mathrm{pH}$.
En fait, le taux d'oxydation du Fe(II) est proportionnel au carré de la concentration d'ions $\mathrm{OH}^{-}$et, donc, de plus en plus rapide avec une montée du pH (SIGG et al., 2006a). De plus, le Fe(II)' (espèces inorganiques de $\mathrm{Fe}(\mathrm{II})$ ) aura aussi tendance à s'associer à des ligands organiques souvent présents en forte concentration par rapport à la concentration du Fe(II)', ce qui pourra stabiliser en quelque sorte le $\mathrm{Fe}(\mathrm{II})^{\prime}$ en condition oxique. En milieu marin, il est ici important de considérer la présence de formes chélatées formées avec d'autres cations compétiteurs comme le $\mathrm{Ca}$ (ex. : Ca-MOD, $\mathrm{Ca}(\mathrm{NTA})^{-1}$, $\left.\mathrm{Ca}(\mathrm{EDTA})^{-2}\right)$ puisque le taux de dissociation de ces derniers complexes sera directement relié à la vitesse de formation de complexes chélates entre le $\mathrm{Fe}(\mathrm{II})^{\prime}$ et ces ligands organiques (NTA = acide nitrilotriacétique; EDTA = acide éthylène diamine tétraacétique). Ainsi, la concentration de $\mathrm{Fe}(\mathrm{II})^{\prime}$ à l'état stationnaire dans l'eau oxygénée serait reliée en grande partie au $\mathrm{pH}$ de l'eau, à l'intensité lumineuse et (en milieu marin) à la cinétique de complexation du Fe(II)' avec les ligands organiques (ANDERSON et MOREL, 1982), et ce, à pression partielle d'oxygène constante, à température constante et à concentration de ligand organique constante (SIGG et al., 2006a).

Le Fe(III), étant un cation de transition trivalent, aura une forte tendance à réagir avec les ions hydroxyles et à former des hydroxo-complexes $\left(\mathrm{Fe}(\mathrm{OH})^{3-x}\right)$ très peu solubles. Il possède aussi une très forte tendance à s'associer avec les ligands organiques comparativement au $\mathrm{Fe}(\mathrm{II})$ (tels la MOD ainsi que des agents chélateurs synthétiques comme le NTA ou l'EDTA) puisqu'il est situé à l'extrémité gauche de la série de IrvingWilliams $\left(\mathrm{Fe}^{3+}>\mathrm{Cu}^{2+}>\mathrm{Co}^{2+} \approx \mathrm{Zn}^{2+}>\mathrm{Fe}^{2+}>\mathrm{Mn}^{2+}\right)(\mathrm{SIGG}$ et al., 2006a). Dans la couche de surface des eaux naturelles, le $\mathrm{Fe}$ (en majorité du $\mathrm{Fe}(\mathrm{III})$ ) sera présent sous forme libre à des concentrations infimes dans les écosystèmes d'eau douce. Par exemple, pour une gamme de lacs échantillonnés à Rouyn-Noranda et à Sudbury (de pH aux alentours de 7), les concentrations de Fe libre calculées avec le logiciel Windermere Humic Aqueous Model (WHAM) (Tipping, 1998) varieraient entre $10^{-19} \mathrm{M}$ et $10^{-16} \mathrm{M}$, soit de 106 à 1010 fois plus faibles que celles du Fe total dissous (K. MUELLER, communication personnelle). Les concentrations de Fe labile (somme des concentrations des hydroxo-complexes) seraient cependant beaucoup plus élevées (de $10^{-9}$ à $10^{-7} \mathrm{M}$ ) et pourraient représenter une bonne proportion $(>20 \%)$ de la concentration de Fe total dissoute, le reste du Fe étant associé à la MOD.

\subsection{Présence et spéciation du manganèse}

Le Mn ionique existe sous la forme de trois états d'oxydation : + II, +III et +IV. Dans les eaux oxygénées, le Mn(II) est la forme la plus soluble, mais la moins stable thermodynamiquement; le $\mathrm{Mn}(\mathrm{III})$ représente une forme métastable peu soluble caractérisée par des oxydes de Mn, et le Mn(IV) constitue la 
forme stable, mais n'est que très peu soluble, se présentant aussi sous forme d'oxydes de Mn (STUMM et MORGAN, 1996). Le Mn possède une faible tendance à s'associer aux ligands inorganiques et organiques comparativement aux autres métaux traces. Cela fait en sorte que le Mn dissous ou $\mathrm{Mn}(\mathrm{II})$ est souvent présent en grande quantité et proportion sous sa forme libre $\left(\mathrm{Mn}^{2+}\right)$ dans les écosystèmes d'eau douce. Par exemple, pour différents lacs de Rouyn-Noranda et de Sudbury, 20 à $80 \%$ du Mn total (concentrations de $\mathrm{Mn}$ total variant entre $5 \cdot 10^{-9} \mathrm{M}$ et $10^{-8} \mathrm{M}$ ) serait sous forme libre selon des calculs thermodynamiques effectués avec le logiciel WHAM (K. MUELLER, communication personnelle). Plusieurs lacs gaspésiens présentent des concentrations totales de $\mathrm{Mn}$ similaires, soit de $10^{-8}$ à $10^{-7} \mathrm{M}$ (C. FORTIN, résultats non publiés).

Le Mn est caractérisé par un cycle redox dynamique et la répartition entre le $\mathrm{Mn}$ (II) soluble et les oxydes de $\mathrm{Mn}$ dépend des taux de réduction ou d'oxydation nets entre les différents états d'oxydation. La réduction des formes de $\mathrm{Mn}$ plus stables (formes oxydées) en milieu aérobie peut se produire par des agents organiques (acides humiques) réducteurs ou par l'effet de la lumière (photoréduction) (SUNDA et HUNTSMAN, 1988). Ensuite, la réoxydation du Mn(II) en $\mathrm{Mn}(\mathrm{III})$ ou $\mathrm{Mn}(\mathrm{IV})$, plus stables thermodynamiquement, peut se produire spontanément ou être catalysée par certains microorganismes. L'oxydation spontanée du Mn(II) dépend de la pression partielle d'oxygène, de la température de l'eau, de la concentration de ligands organiques et surtout $\mathrm{du} \mathrm{pH}$ (le taux d'oxydation du $\mathrm{Mn}(\mathrm{II})$ est proportionnel au carré de la concentration des ions hydroxyles en solution). Il faut aussi noter que l'oxydation du $\mathrm{Mn}$ (II) peut être autocatalysée par la présence d'oxydes de Mn (STUMM et MORGAN, 1996; VON LANGEN et al., 1997). En outre, les microorganismes (bactéries et algues eucaryotes) présents dans la colonne d'eau accélèrent l'oxydation du $\mathrm{Mn}$ (II) en formant des oxydes de Mn à leur surface (KNAUER et al., 1999; RICHARDSON et al., 1988; RICHARDSON et STOLZENBACH, 1995). Le potentiel de croissance de ces microorganismes (optimum de température, de luminosité et de nutriments) stimulera donc la vitesse d'oxydation du $\mathrm{Mn}(\mathrm{II})$, qui serait autrement plutôt lente (cinétique d'oxydation du $\mathrm{Mn}(\mathrm{II})$ relativement lente). Ainsi, le temps de résidence du $\mathrm{Mn}(\mathrm{II})$ serait égal à plusieurs mois en l'absence de microorganismes tandis qu'il pourrait être beaucoup plus bref, de l'ordre de plusieurs heures (ordre de grandeur de la vitesse d'oxydation du Mn devient similaire à celle du $\mathrm{Fe}$ ) lorsque les microorganismes sont pris en considération (PANKOW et MORGAN, 1981; SUNDA et HUNTSMAN, 1988).

\subsection{Présence et spéciation du zinc}

Le $\mathrm{Zn}$ ionique ne comporte qu'un état d'oxydation, le $\mathrm{Zn}$ (II). Il est classifié comme un métal intermédiaire (possédant des caractéristiques des cations de classe B et de classe A). Il a donc tendance à former des complexes avec les groupements thiols (métaux mous) ainsi qu'avec les groupements hydroxyles ou carboxyliques (métaux durs). Ce métal possède en général une spéciation chimique relativement simple comparativement aux autres métaux traces essentiels étudiés. Il se complexe relativement peu (comparativement au $\mathrm{Cu}$ et au $\mathrm{Fe}$ ) aux ligands inorganiques et à la MOD dans les eaux douces oligotrophes d'un $\mathrm{pH}$ près de 7 et peut donc être présent en proportion appréciable sous forme libre.

Prenons l'exemple d'une série de lacs situés dans un gradient de contamination de $\mathrm{Zn}$ provenant des fonderies de métaux à Rouyn-Noranda étudiés par FORTIN et al. (2010). Les concentrations totales mesurées de $\mathrm{Zn}$ seraient près de $10^{-8} \mathrm{M}$ pour les lacs non contaminés et atteindraient $2 \cdot 10^{-6} \mathrm{M}$ pour les lacs contaminés. Pour l'ensemble de ces lacs, moins de $45 \%$ du Zn total était complexé à la MOD faisant en sorte que la proportion de $\mathrm{Zn}^{2+}$ par rapport au $\mathrm{Zn}$ total était de plus de $55 \%$. Il faut noter que la proportion de $\mathrm{Zn}^{2+}$ peut être beaucoup plus faible dans les lacs eutrophes en été. Par exemple, la proportion de $\mathrm{Zn}^{2+}$ par rapport au $\mathrm{Zn}$ total dissous était d'environ $7 \%$ dans le lac Greifen, un lac eutrophe suisse (XUE et al., 1995; XUE et SIGG, 1994). Dans ce lac, des concentrations de $\mathrm{Zn}^{2+}$ variant de $3 \cdot 10^{-10}$ à $3 \cdot 10^{-9} \mathrm{M} \mathrm{Zn}^{2+}$ furent mesurées.

\section{MÉCANISMES D'ACCUMULATION DES MÉTAUX ESSENTIELS}

Cette section s'attarde aux systèmes de transport présents chez les membranes plasmiques algales qui permettent l'internalisation et l'exportation des cinq métaux de transition traités dans la présente revue de littérature $(\mathrm{Co}, \mathrm{Cu}, \mathrm{Fe}, \mathrm{Mn}$ et $\mathrm{Zn}$ ). Ces métaux sont transportés dans le cytoplasme des algues (ou exportés des cellules) à l'aide de différents systèmes de transport membranaires. Ces systèmes de transport sont composés de protéines incorporées dans la membrane plasmique des cellules. Les systèmes permettant l'internalisation des métaux dans les cellules sont classés dans différentes familles selon leur structure et caractéristiques : les familles CTR $(\mathrm{Cu}$ transporter), ZIP (ZRT/IRT-like proteins), NRAMP (natural resistance-associated macrophage proteins), FTR (Fe transporter). Les systèmes de transport permettant l'exportation des métaux des cellules font partie essentiellement de deux catégories : les P-type ATPase et les CDF (cation diffusion facilitator) (BLABYHAAS et MERCHANT, 2012). 
Pour une discussion plus détaillée des caractéristiques des systèmes de transport des métaux des algues et des plantes, le lecteur est référé aux revues de littérature de ARGÜELLO et al. (2007), BLABY-HAAS et MERCHANT (2012), HALL et WILLIAMS (2003), HANIKENNE et al. (2005), KIM et al. (2008), KRÄMER et al. (2007), NEVO et NELSON (2006), REID (2001), ROSAKIS et KÖSTER (2004), et YRUELA (2013).

\subsection{Types de transporteurs membranaires: fonctions et sources d'énergie}

Les systèmes ZIP transportent passivement les métaux dans les cellules à l'aide du gradient de concentration transmembranaire en métaux et ne requièrent donc pas directement d'énergie biochimique (adénosine-triphosphate [ATP], nicotinamide adénine dinucléotide phosphate [NADPH]) (BLABY-HAAS et MERCHANT, 2012). Ce gradient de concentration du métal libre de part et d'autre de la membrane plasmique serait favorable au transport des métaux dans les cellules algales puisque les concentrations intracellulaires de métaux libres dans le cytoplasme seraient extrêmement faibles, c'est-à-dire entre $10^{-21} \mathrm{M}$ et $10^{-18} \mathrm{M} \mathrm{Cu}^{2+}$ libre et environ $10^{-15} \mathrm{M} \mathrm{Zn}^{2+}$ libre (KRÄMER et al., 2007). Ces concentrations correspondent à moins d'un ion métallique libre par cellule et on peut donc conclure qu'il n'y a pas de métal libre qui persiste dans le cytoplasme des cellules; les métaux essentiels seraient plutôt liés à des protéines appelées métallochaperones participant à l'homéostasie des métaux dans les cellules vivantes (KRÄMER et al., 2007).

Toutefois, les systèmes de transport CTR et FTR peuvent consommer de l'énergie biochimique indirectement, car ils peuvent être couplés à des réductases membranaires qui consomment du NADPH afin de réduire le $\mathrm{Cu}$ et le Fe avant leur transport (HERBIK et al., 2002; PAGE et al., 2009; XUE et al., 1998).

Pour ce qui est des systèmes NRAMP, le transport des métaux serait couplé au transport d'un proton qui lui serait entretenu par le potentiel membranaire négatif (BLABYHAAS et MERCHANT, 2012; NEVO et NELSON, 2006). Ce potentiel membranaire négatif est rendu possible chez les cellules végétales, les fungi et les protistes grâce à une enzyme membranaire, la $\mathrm{H}^{+}$-ATPase, qui pompe des protons hors des cellules en consommant de l'ATP (et donc crée une charge négative sur la face interne de la membrane plasmique) (PALMGREN, 2001). Les systèmes NRAMP utilisent donc indirectement de l'énergie biochimique (ATP) pour permettre le transport des métaux dans les cellules.

Les systèmes P-type ATPase sont des transporteurs actifs qui utilisent directement l'ATP comme source d'énergie.
Finalement, les systèmes CDF peuvent exporter les métaux des cellules en couplant l'exportation de métaux à l'internalisation du potassium ou de protons par des systèmes de transport qui utilisent le potentiel électrique membranaire comme force motrice (système antiport). Les systèmes CDF utilisent donc indirectement l'ATP cellulaire qui est la source d'énergie à l'origine de la génération du potentiel électrique membranaire chez les algues (BLABY-HAAS et MERCHANT, 2012).

\subsubsection{Systèmes de transport du cobalt}

Les concentrations de Co accumulées par les algues eucaryotes marines (FINKEL et al., 2006; HO et al., 2003) et d'eau douce (MERCHANT et al., 2006) sont, d'ordre général, beaucoup plus faibles que celles des autres micronutriments cationiques. Les mécanismes de transport transmembranaires du Co chez les algues sont peu connus comparativement à ceux des autres métaux traités dans la présente revue de littérature. Il est possible que le Co inorganique soit pris en charge par des transporteurs de métaux cationiques divalents peu sélectifs (NRAMP). En effet, ce type de transporteur est connu comme étant impliqué dans le transport de $\mathrm{Co}$ (II) chez plusieurs eucaryotes (DALCORSO et al., 2008). Certaines espèces d'algues (ex. : Thalassiosira pseudonana) seraient aussi capables d'accumuler la vitamine B12 (vitamine contenant le Co) directement de la solution puisqu'ils exigent cette vitamine pour leur croissance, mais ne possèdent pas les enzymes nécessaires pour la synthétiser.

\subsubsection{Systèmes de transport du cuivre}

Presque toutes les algues dont le génome fut séquencé contiennent au moins un gène codant pour un transporteur de Cu membre de la famille CTR (BLABY-HAAS et MERCHANT, 2012). Les systèmes de transport CTR2 et CTR3 furent isolés des membranes plasmiques de Chlamydomonas reinhardtii par transfert de protéines ou buvardage de western (PAGE et al., 2009). La capacité de ces systèmes à transporter le $\mathrm{Cu}$ fut aussi validée chez la levure Saccharomyces cerevisiae (mais pas directement chez $C$. reinhardtii) en transformant génétiquement des mutants de cette levure ayant perdu la capacité de synthétiser leur propre système de transport de $\mathrm{Cu}$. Ces systèmes de transport CTR sont spécifiques au $\mathrm{Cu}(\mathrm{I})$ et sont associés à des enzymes membranaires réduisant le $\mathrm{Cu}(\mathrm{II})$ en $\mathrm{Cu}(\mathrm{I})$ en milieu aérobie. Notons aussi que la réductase cuprique de même que la réductase ferrique peuvent réduire le $\mathrm{Cu}(\mathrm{II})$ en $\mathrm{Cu}(\mathrm{I})$ à la surface des cellules algales suggérant que le $\mathrm{Cu}$ est pris en charge par les algues grâce à des systèmes de transport CTR (HILL et al., 1996; HUDSON, 1998).

Des transporteurs membranaires de type NRAMP pourraient aussi être impliqués dans la prise en charge $\mathrm{du} \mathrm{Cu}$ chez au moins une espèce d'algue (C. reinhardtii) puisqu'une surexpression de ce gène DMT1 algal chez des souches mutantes de levures augmentait leur sensibilité à la 
toxicité du Cu (ROSAKIS et KÖSTER, 2005). Mentionnons toutefois que l'expression du gène DMT1 chez des levures et la démonstration de ses capacités à transporter le $\mathrm{Cu}$ ne veulent pas nécessairement dire que le gène DMT1 est exprimé chez C. reinhardtii. Ce type de transporteur étant reconnu comme étant davantage un système de faible affinité (ne demandant pas de couplage à une enzyme réductrice), pourrait peut-être transporter le $\mathrm{Cu}$ (II) directement, mais cela demeure spéculatif. D'autres études devront être réalisées chez les algues afin de connaître le substrat réel de ce transporteur NRAMP, le $\mathrm{Cu}(\mathrm{I})$ ou le $\mathrm{Cu}(\mathrm{II})$.

Quelques indices obtenus par la biologie moléculaire suggèrent que le $\mathrm{Cu}$ intracellulaire peut être excrété des cellules algales par des systèmes de la famille des P-type ATPase. Le génome de l'algue Cyanidioschyzon merolae contient une séquence génétique similaire à celle codant pour le système de transport ATP7B (de la famille des P-type ATPase). Ce système peut permettre l'excrétion du $\mathrm{Cu}$ hors des cellules humaines en présence d'un excès de $\mathrm{Cu}$. Il est donc possible que ce système de transport participe à l'excrétion $\mathrm{du} \mathrm{Cu} \mathrm{chez}$ C. merolae exposée à de grandes concentrations de $\mathrm{Cu}$. De plus, un transporteur membre des P-type ATPase, nommé CTP3, est présent dans le génome de $C$. reinhardtii. Ce système de transport est similaire au transporteur HMA5 d'Arabidopsis et pourrait contribuer à la détoxication $\mathrm{du} \mathrm{Cu}$ par exocytose chez C. reinhardtii (BLABY-HAAS et MERCHANT, 2012).

\subsubsection{Systèmes de transport du fer}

Le Fe peut être pris en charge dans les cellules algales par deux mécanismes : 1) Le $\mathrm{Fe}(\mathrm{III})$ peut être réduit, réoxydé à la surface cellulaire et transporté dans les cellules; 2) Le $\mathrm{Fe}(\mathrm{II})$ peut être transporté dans les cellules par des protéines transmembranaires de la famille des NRAMP. Notons aussi qu'il est possible que des complexes de $\mathrm{Fe}$ formés avec des sidérophores puissent être internalisés directement dans les cellules algales à l'aide d'un mécanisme encore inconnu, mais ce troisième mécanisme, qui est bien documenté chez les bactéries (SHELDON et HEINRICHS, 2015), demeure hypothétique à ce jour pour les algues.

La première voie de prise en charge du $\mathrm{Fe}$ fait intervenir un système de transport très spécifique au $\mathrm{Fe}$ (III) impliquant plusieurs étapes de réduction, oxydation et translocation. La première étape de ce mécanisme de transport constitue la réduction du $\mathrm{Fe}$ (III) en $\mathrm{Fe}$ (II) par une enzyme transmembranaire (la réductase ferrique) utilisant le NADPH comme source d'énergie. Chez C. reinhardtii, la réductase ferrique (FRE1) est située dans la membrane plasmique et son activité est régulée à la hausse lors d'une carence en Fe (BLABY-HAAS et MERCHANT, 2012). Les diatomées marines T. pseudonana et Phaeodactylum tricornutum auraient aussi les gènes codant pour cette enzyme (ALLEN et al., 2008; KUSTKA et al., 2007). Deuxièmement, le Fe(II) est réoxydé par une enzyme membranaire, la ferroxydase multicuivre (HERBIK et al., 2002). Cette enzyme fut d'ailleurs isolée dans la membrane plasmique de $C$. reinhardtii (enzyme appelé FOX1). La troisième et dernière étape consiste à transporter le $\mathrm{Fe}^{3+}$ dans les cellules grâce à une perméase (FTR1) suivant son gradient de concentration. Les séquences génétiques homologues de cette perméase FTR1 sont présentes chez plusieurs espèces de phytoplancton (BLABY-HAAS et MERCHANT, 2012).

Le deuxième mécanisme est beaucoup plus simple que le premier et ne fait intervenir que des protéines transmembranaires de la famille des NRAMP. Le $\mathrm{Fe}^{2+}$ se lie à ce système de transport (symport $\mathrm{Fe}^{2+}: \mathrm{H}^{+}$) et est transporté dans les cellules. Une séquence génétique homologue aux gènes codant pour les transporteurs NRAMP chez les levures fut récemment identifiée chez l'algue $C$. reinhardtii (ROSAKIS et KÖSTER, 2005). Cette équipe de recherche a montré que l'expression du gène des NRAMP (nommé DMT1) isolé chez C. reinhardtii était impliquée dans le transport du Fe (présumément le Fe(II); état rédox non défini) chez la levure (et non chez $C$. reinhardtii directement) en étudiant la croissance de levures exprimant le gène DMT1. De façon intéressante, la prise en charge du Fe en présence de concentrations de Fe limitant la croissance de C. reinhardtii n'est pas affectée par des concentrations de $\mathrm{Cu}$ limitant la croissance, ce qui suggère la présence d'un système de transport du Fe indépendant de celui nécessitant l'enzyme oxydase multicuivre, soit le transport de haute affinité du Fe(III) (LA FONTAINE et al., 2002). Il semble raisonnable de spéculer que ce système de transport du Fe indépendant serait constitué des transporteurs NRAMP puisque KUSTKA et al. (2007) ont démontré une régulation à la hausse du gène associé aux transporteurs NRAMP chez l'algue marine T. pseudonana en présence de faibles concentrations de $\mathrm{Fe}(\mathrm{III})$ (et de concentration de $\mathrm{Fe}(\mathrm{II})$ négligeable par rapport à celle du $\mathrm{Fe}(\mathrm{III})$ dans le noir et à $\mathrm{pH}>8$ ). L'induction du système de prise en charge du Fe(II) par les transporteurs NRAMP pour maximiser la capacité de prise en charge du Fe se ferait cependant au coût d'une diminution de la sélectivité des transporteurs du Fe (KRÄMER et al., 2007).

Une troisième voie d'internalisation du $\mathrm{Fe}$ chez le phytoplancton eucaryote, nécessitant la production et la prise en charge spécifique des complexes Fe-sidérophores, demeurent encore hypothétique. Certaines espèces de phytoplancton eucaryote produiraient des sidérophores, dont trois chlorophycées (Dunaliella tertiolecta, Scenedesmus incrassatulus, Closterium aciculare) (NAITO et al., 2004; TRICK et al., 1983b), une dinoflagellé (Prorocentrum minimum) (TRICK et al., 1983a, 1983b), une diatomée (T. pseudonana) (TRICK et al., 1983b), et une cryptophycée (Rhodomonas ovalis) (NAITO et al., 2001). Chez plusieurs diatomées, le Fe(III) lié au sidérophore serait réduit en Fe(II) et internalisé par le mécanisme 1 décrit plus haut (HOPKINSON et MOREL, 2009). Toutefois, certaines algues vertes (prasinophytes) 
n'auraient pas d'oxydase multicuivre (FOX1) et de perméase du Fe (FTR1) et ne pourraient donc pas utiliser le mécanisme de transport du Fe par réduction/oxydation (mécanisme 1 énoncé plus haut). Ils ont plutôt des gènes présentant des similitudes avec les protéines de transport membranaire des procaryotes impliquées dans la reconnaissance des sidérophores (HOPKINSON et MOREL, 2009; PALENIK et al., 2007). Cela suggère que ces prasinophytes pourraient interagir directement avec les complexes Fe-sidérophores afin de subvenir à leur besoin en Fe.

\subsubsection{Systèmes de transport du manganèse}

Des recherches récentes en biologie moléculaire ont suggéré que chez l'algue $C$. reinhardtii, le Mn pourrait être transporté par des protéines membranaires (nommées DMT1) de la famille des NRAMP. En effet, une surexpression du gène DMT1 chez des souches mutantes de levures augmentait leur sensibilité à la toxicité du Mn (ROSAKIS et KÖSTER, 2005). De plus, l'expression du gène codant pour le transporteur DMT1 (isolé chez $C$. reinhardtii) chez des souches mutantes de levures incapables de croître en présence de faibles concentrations de Mn restaure le potentiel de croissance des levures. Ainsi, tout dépendant de la capacité du gène DMT1 à être exprimé chez C. reinhardtii, il est possible que ce transporteur de la famille des NRAMP participe à la prise en charge du Mn chez cette espèce d'algues comme chez les levures.

\subsubsection{Systèmes de transport membranaire du zinc}

Chez l'algue $C$. reinhardtii, les transporteurs membranaires de type NRAMP ne seraient pas impliqués dans la prise en charge du Zn. En effet, la croissance des souches de levures exprimant le gène DMT1 (associé à la production de transporteurs NRAMP chez $C$. reinhardtii) n'était pas supérieure à celle ne possédant pas le gène DMT1 en présence de concentrations de Zn qui limite la croissance. De plus, une surexpression du gène DMT1 chez des souches mutantes de levures n'augmentait pas leur sensibilité à la toxicité du Zn (ROSAKIS et KÖSTER, 2005). Toutefois, la découverte de séquences génétiques chez C. reinhardtii similaires à celles qui codent pour les transporteurs de faible (ZRT1) et de haute affinité (ZRT2) du Zn (de la famille des protéines ZIP) chez la levure $S$. cerevisiae suggère l'expression de deux types de transporteurs du $\mathrm{Zn}$ de la famille ZIP chez $C$. reinhardtii (HANIKENNE et al., 2005; ROSAKIS et KÖSTER, 2004), tout comme les courbes de prise en charge sigmoïdales obtenues lors d'expériences de prise en charge du Zn à court terme chez différentes espèces phytoplanctoniques (voir section 4.2.5). Le Zn pourrait aussi être exporté du cytosol par des transporteurs HMA2 (de la famille des P-type ATPase) dont la séquence génétique est présente chez des prasinophytes et des diatomées. Toutefois, les algues vertes C. reinhardtii, Chlorella variabilis et Volvox carteri ainsi que l'algue rouge $C$. merolae ne posséderaient pas la séquence génétique de ces transporteurs HMA2 (BLABY-HAAS et
MERCHANT, 2012). Certaines espèces d'algues possèdent des gènes codant pour la synthèse du transporteur MTP1 (de type CDF). (BLABY-HAAS et MERCHANT, 2012). Ces systèmes CDF seraient peu spécifiques et pourraient permettre l'excrétion de nombreux métaux ( $\mathrm{Zn}, \mathrm{Mn}, \mathrm{Cd})$ chez les plantes et les levures. Toutefois, il n'y a que peu d'informations spécifiques aux algues à ce sujet (BLABY-HAAS et MERCHANT, 2012).

\section{MODẼLES DE L'ION LIBRE ET MODĖLE DU LIGAND BIOTIQUE}

L'avènement de logiciels au début des années 1970 a changé radicalement la façon de voir et de comprendre l'impact des métaux toxiques chez les organismes aquatiques. Au lieu de se concentrer sur l'impact des métaux chez les organismes cibles, l'attention s'est tournée vers les différentes espèces chimiques des métaux en solution. Les concentrations de ces espèces pouvaient désormais être rapidement calculées à l'aide d'algorithmes de calculs intégrés aux logiciels informatiques. De plus, les concentrations des espèces présentes en très faibles concentrations (et donc difficilement analysables) pouvaient maintenant être estimées (TEMPLETON et al., 2000).

L'étude des interactions entre les différentes espèces métalliques et les cellules phytoplanctoniques a commencé il y a plus de 30 ans avec les travaux pionniers de SUNDA et GUILLARD (1976) mettant en relation l'activité de l'ion cuprique et sa toxicité chez une espèce d'algue marine. Le modèle de l'ion libre (MIL) fut ensuite développé sous la base de nombreuses expérimentations effectuées vers la deuxième moitié des années 1970 (MOREL, 1983). Ce modèle stipule que l'accumulation et la toxicité des métaux sont proportionnelles à l'activité de l'ion libre $\mathrm{M}^{\mathrm{z+}}$ (aquo-ion ou $\mathrm{M}\left(\mathrm{H}_{2} \mathrm{O}\right) \mathrm{n}^{\mathrm{Z+}}$ ) en solution. Une revue de littérature de CAMPBELL (1995) portant sur l'ensemble des recherches effectuées sur le MIL (avant 1995) démontre bien que la réponse biologique de différents organismes aquatiques (algues, invertébrés, poissons) varie en fonction de l'ion libre (pour 52 des 59 cas étudiés) lors d'expositions réalisées en laboratoire à court terme à différents métaux $(\mathrm{Cd}, \mathrm{Cu}, \mathrm{Fe}, \mathrm{Mn}, \mathrm{Ni}, \mathrm{Pb}, \mathrm{Zn})$, et ce, à $\mathrm{pH}$ et dureté constants, ainsi qu'en présence de complexes métalliques inorganiques hydrophiles.

Puisque les conditions chimiques des eaux douces sont beaucoup plus variables que celles de l'eau de mer et que ces conditions chimiques peuvent avoir un impact important sur cette relation simple entre le $\mathrm{M}^{\mathrm{z}}$ et les organismes aquatiques, le raffinement du MIL pour les eaux douces s'imposait. Ainsi, l'intégration des effets protecteurs de certains cations $\left(\mathrm{H}^{+}, \mathrm{Ca}^{2+}\right.$, $\left.\mathrm{Mg}^{2+}\right)$ au MIL a mené à la formulation du modèle du ligand 
biotique (MLB) (CAMPBELL et al., 2002; DI TORO et al., 2001; PAQUIN et al., 2002a). Ce modèle porte davantage attention aux sites de la membrane cellulaire physiologiquement actifs que ne faisait le MIL. Il est important de noter que le MLB n'est qu'un modèle dérivé du MIL et que la prise en charge et la toxicité reste toujours directement proportionnelle à la concentration de l'ion libre, pour une dureté et un $\mathrm{pH}$ constants.

Malgré l'ensemble des recherches effectuées sur le MLB au cours des années 2000, ce modèle se doit encore d'être raffiné afin de mieux prédire l'accumulation et la toxicité chronique des métaux dans des environnements complexes de composition variable. À ce jour, les bases fondamentales régissant les interactions entre les cations majeurs $\left(\mathrm{Ca}^{2+}\right.$ et $\left.\mathrm{Mg}^{2+}\right)$, le $\mathrm{pH}$, les métaux et les membranes cellulaires demeurent encore peu comprises, même si beaucoup de progrès a été réalisé à ce sujet au cours des dernières années. Il en ressort donc qu'il n'est pas encore possible de monter un modèle de type MLB incluant l'ensemble des processus clés régissant l'accumulation et la toxicité des métaux pour en prédire la toxicité. De ce fait, des relations empiriques sont souvent développées afin de prédire adéquatement la toxicité aiguë ou chronique des métaux chez les organismes aquatiques à l'intérieur de plans d'eau à la dureté et au $\mathrm{pH}$ variable (DE SCHAMPHELAERE et JANSSEN, 2004, 2006; DE SCHAMPHELAERE et al., 2005; DELEEBEECK et al., 2009a, 2009b; HEIJERICK et al., 2002a, 2002b). Ces modèles ont toutefois une portée limitée et d'autres approches plus déterministes visant à inclure les mécanismes physiologiques d'accumulation et de toxicité dans le MLB ont été proposées. Ces approches démontrent un fort potentiel afin de bien prédire la toxicité des métaux dans des milieux simplifiés de composition variable même si beaucoup de travail reste encore à faire avant de pouvoir prédire adéquatement la toxicité des métaux « en milieu naturel » avec ces modèles déterministes (LAVOIE et al., 2012a; PAQUIN et al., 1999).

Les succès (malgré certaines limites) du MLB ont conduit à la mise au point de logiciels (ex. : Hydroqual; http:// www.hydroqual.com/wr_blm.html) permettant de déterminer des critères de qualité de l'eau spécifiques à partir de la composition chimique des plans d'eau étudiés. Le MLB est même utilisé aujourd'hui pour dériver les critères de qualité de l'eau pour le Cu aux États-Unis (US EPA) et pour l'analyse de risque écotoxicologique de plusieurs métaux par l'Union européenne ((EUROPEAN COMMISSION, 2011; MEYER et al., 2015; USEPA, 2007). Même si le MLB est un outil toujours en développement, l'utilisation de ce modèle permet de prédire beaucoup plus adéquatement la toxicité des métaux en milieu aquatique comparativement à l'approche classique. Cette ancienne approche n'était basée que sur la concentration totale de métaux en solution ou la concentration de métaux récupérés suite à une acidification de l'échantillon.

\subsection{Prémisses du modèle et théorie}

Pour exercer une réponse toxique ou être accumulés chez les organismes aquatiques, les métaux doivent interagir avec la surface biologique et, normalement, être transportés à l'intérieur des cellules vivantes. L'interaction d'un métal avec un organisme aquatique peut généralement être décrite par les processus suivants qui sont présentés schématiquement à la figure 1 (CAMPBELL et FORTIN, 2013; CAMPBELL et al., 2002; SLAVEYKOVA et WILKINSON, 2005) :

1. Le métal diffuse relativement rapidement de la solution vers la surface biologique;

2. Le métal se lie relativement rapidement à des sites passifs dans la couche de protection de la cellule (comme la paroi cellulaire) ou à des sites de la surface extérieure de la membrane plasmique. La membrane plasmique peut contenir des sites physiologiquement inertes (la liaison du métal à ces sites ne perturbe pas les fonctions cellulaires et le métal ne s'accumule pas dans les cellules) ou encore des sites physiologiquement actifs (liaison du métal à une enzyme membranaire, un transporteur protéique ou un canal ionique pouvant effectuer l'internalisation du métal et participer au métabolisme cellulaire);

3. Le métal est internalisé par la cellule par des systèmes de transport spécialisés de cations (transport passif facilité) à travers la membrane plasmique. Normalement, l'internalisation s'avère être l'étape limitante du processus de prise en charge des métaux, ce qui mène à un état d'équilibre entre l'ion métallique libre en solution et la surface biologique.

Le processus de liaison des métaux à la surface biologique est décrit à l'aide des huit équations chimiques ci-dessous. En présence d'un métal $\mathrm{M}^{\mathrm{z}}$, d'un ligand $\mathrm{L}$ (les charges sont omises par souci de simplicité), un équilibre se produit dans le milieu étant caractérisé par une constante d'équilibre $K_{1}$ (Équations 1 et 2).

$$
\begin{gathered}
\mathrm{M}^{\mathrm{z}+}+\mathrm{L} \stackrel{K_{1}}{\longleftrightarrow} \mathrm{ML} \\
K_{1}=\frac{[\mathrm{ML}]}{\left[\mathrm{M}^{2+}\right][\mathrm{L}]}
\end{gathered}
$$

L'interaction entre $\mathrm{M}^{2+}$ et les sites cellulaires physiologiquement actifs, $-\mathrm{X}$-cellule, peut être décrite par une réaction de complexation de surface où la constante conditionnelle d'équilibre est notée $K_{2} ;\{\}$ et [ ] indiquent respectivement les concentrations à la surface biologique et dans le milieu (Équations 3 et 4).

$$
\mathrm{M}^{z^{+}}+{ }^{-} \mathrm{X} \text {-cellule } \stackrel{K_{2}}{\longleftrightarrow} \mathrm{M}-\mathrm{X} \text {-cellule }
$$




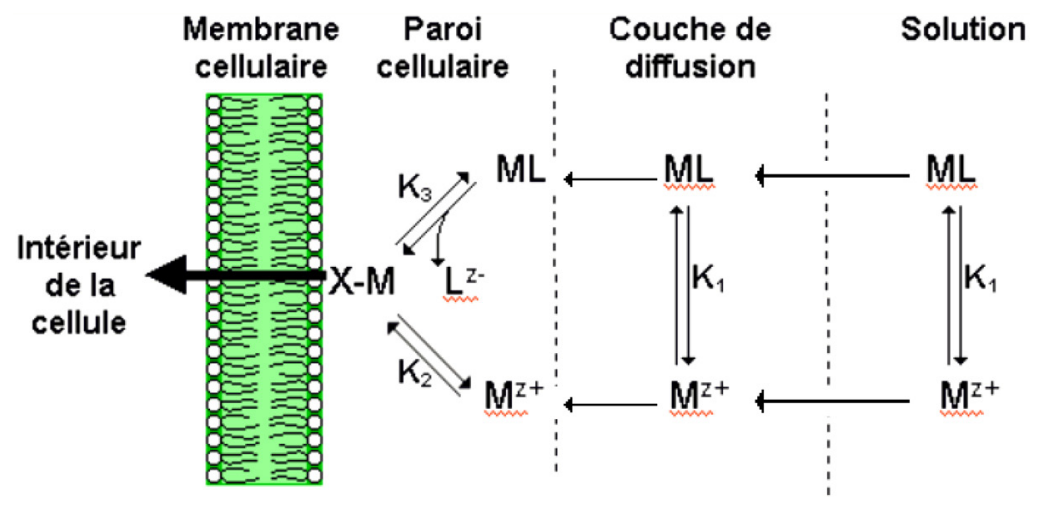

Figure 1. Représentation conceptuelle des interactions métaux-organismes. $\mathrm{M}^{\mathrm{z}+}$ = ion métallique libre; $\mathrm{ML}=$ métal complexé; $\mathrm{L}^{\mathrm{z}-}=$ ligand (acide aminé, citrate, $\mathrm{S}_{2} \mathrm{O}_{3}{ }^{2-}, \mathrm{CO}_{3}{ }^{2-}, \mathrm{Cl}^{-}$, etc.); $\mathrm{M}-\mathrm{X}=$ métal complexé à la surface cellulaire. Figure modifiée de CAMPBELL (1995). Conceptual model of metal-organism interactions. $M^{k^{+}}=$free metal ion; $M L=$ complexed metal; $L^{z-}=$ ligand (amino acid, citrate, $\mathrm{S}_{2} \mathrm{O}_{3}{ }^{2-}$, $\mathrm{CO}_{3}^{2-}, \mathrm{Cl}$, etc.); $\mathrm{M}-\mathrm{X}=$ metal complexed at the cell surface. Figure modified from CAMPBELL (1995).

$$
\{\mathrm{M}-\mathrm{X} \text {-cellule }\}=K_{2}\{-\mathrm{X} \text {-cellule }\}\left[\mathrm{M}^{\mathrm{z}+}\right]
$$

En faisant les hypothèses que 1) la concentration des sites cellulaires physiologiquement actifs (-X-cellule) demeure constante (simplification raisonnable lorsque la concentration de métal dans le milieu est faible), 2) les sites ${ }^{-X}$-cellule sont loin d'être saturés de métaux (-X-cellule >> M-X-cellule) et 3) le temps d'exposition est court, la concentration du métal d'intérêt lié aux sites physiologiquement actifs, internalisés et/ ou qui entraînera une réponse biologique varie linéairement en fonction de la concentration de $\mathrm{M}^{z+}$ (Équation 4).

Une situation similaire à celle décrite ci-dessus prévaut lorsqu'un complexe métallique (ML) est l'espèce réagissant par échange de ligands (cas analogue à la prise en charge de complexes inorganiques labiles; voir section 4.2.3) à la surface cellulaire (Équation 5).

$$
\begin{array}{r}
\mathrm{ML}+{ }^{-\mathrm{X}} \text {-cellule } \stackrel{K_{3}}{\longrightarrow} \mathrm{M} \text {-X-cellule }+\mathrm{L} \\
\frac{[\mathrm{ML}]}{[\mathrm{L}]}=K_{1}\left[\mathrm{M}^{\mathrm{z+}}\right] \\
\{\mathrm{M} \text {-X-cellule }\}=K_{3} \frac{\{-\mathrm{X} \text {-cellule }\}[\mathrm{ML}]}{[\mathrm{L}]} \\
\{\mathrm{M}-\mathrm{X} \text {-cellule }\}=K_{3} \cdot K_{1}\left\{{ }^{-\mathrm{X} \text {-cellule }\}\left[\mathrm{M}^{\mathrm{z}}\right]}\right.
\end{array}
$$

En réarrangeant l'équation 2, on obtient l'équation 6 que l'on peut substituer dans l'équation 7 afin d'obtenir l'équation 8. Cette dernière équation montre que la concentration du complexe $\mathrm{M}-\mathrm{X}$-cellule varie en fonction de la concentration de l'ion métallique libre en solution lorsque le complexe ML réagit par échange de ligands à la surface cellulaire (CAMPBELL et al., 2002). La liaison des métaux aux sites physiologiquement actifs demeure dépendante de l'espèce métallique libre de façon identique à la relation établie à l'équation 4 , où nous ne considérerions que l'ion libre $\left(\mathrm{M}^{2+}\right)$ et non le complexe ML. Ainsi, la prise en charge et la toxicité des métaux par les organismes aquatiques sont grandement influencées par la concentration de l'ion métallique libre en conditions d'équilibre. Comme tout modèle, le MLB a des limites. Quelques cas d'exceptions au modèle sont décrits dans la section suivante.

\subsection{Limites du modèle}

Le MLB est un modèle développé pour prédire l'accumulation et la toxicité des métaux présents dans la phase dissoute. Le MLB, même si fort utile pour prédire la toxicité des métaux dissous, ne peut établir à lui seul de diagnostic clair quant au danger potentiel des métaux pour un écosystème donné (HERING, 2009). Il est donc important de garder en tête qu'une gestion intégrée de la toxicité des métaux chez les communautés d'organismes colonisant les milieux aquatiques se doit aussi de considérer d'autres approches prenant en compte la nourriture comme voie possible d'exposition aux métaux chez les organismes consommateurs (BIRD et KALFF, 1987); voir le modèle biodynamique dans LUOMA et RAINBOW (2008). Il est aussi important de considérer les possibles effets néfastes des métaux sur un maillon de la chaîne alimentaire qui pourraient avoir des répercussions sur la survie 
d'un autre maillon de la chaîne trophique par une modulation de la prédation, du broutage ou de la qualité/disponibilité de la nourriture (LUOMA et RAINBOW, 2008).

Même si l'approche mathématique relativement simple du MLB s'est avérée fort utile pour la prédiction de la toxicité aigüe des métaux chez différents organismes aquatiques (CAMPBELL, 1995), ce modèle comporte quand même des limites et n'est pas applicable dans toutes les situations pour prédire la toxicité des métaux présents dans la phase aqueuse. En effet, quelques cas où le MLB ne pouvait prédire adéquatement la prise en charge et la toxicité des métaux chez les organismes aquatiques ont été retracés dans la littérature (CAMPBELL, 1995; CAMPBELL et al., 2002; SLAVEYKOVA et WILKINSON, 2005; ZHAO et al., 2016). Les sections 4.2.1 à 4.2.7 qui suivent présentent sept exemples de dérogations au MLB, établissant ainsi les limites de ce modèle.

\subsubsection{Transport membranaire par une autre voie qu'un système de transport de cations}

Pour que le MLB s'applique, les métaux se doivent d'être transportés par des systèmes de transport membranaires de cations de sorte que seul le métal libre se lie aux sites physiologiquement actifs (-X-cellule). Or, il est désormais connu que certains complexes métalliques peuvent emprunter une voie alternative pour pénétrer dans la cellule. Premièrement, les complexes métalliques neutres lipophiles peuvent pénétrer à travers la bicouche lipidique des membranes algales par diffusion passive. Citons par exemple le complexe inorganique $\mathrm{HgCl}_{2}{ }^{0}$ et le $\mathrm{CH}_{3} \mathrm{HgCl}^{0}$ (MASON et al., 1996) de même que certains complexes formés avec le diéthyldithiocarbamate (DDC), l'éthylxanthate (XANT) et la 8-hydroxyquinoline (oxine ou $\mathrm{Ox}$ ) tels que $\mathrm{Pb}(\mathrm{DDC}){ }_{2}{ }^{0}, \mathrm{Cu}(\mathrm{Ox})_{2}{ }_{2}$ et $\mathrm{Cd}(\mathrm{XANT}){ }_{2}{ }^{0}$ (BOULLEMANT et al., 2009; FLORENCE et al., 1992; LAVOIE et al., 2012c; PHINNEY et BRULAND, 1994; STAUBER et FLORENCE, 1987). Deuxièmement, certains complexes hydrophiles chargés négativement (formés avec un métabolite de faible poids moléculaire, le citrate, ou un ligand inorganique, le thiosulfate) peuvent être accumulés par inadvertance par des transporteurs membranaires spécifiques à ces métabolites ou ces ligands inorganiques. Par exemple, les complexes organiques formés avec le citrate, $\mathrm{Cd}(\text { citrate })^{-1}, \mathrm{Zn}$ (citrate) $^{-1}$ (ERRÉCALDE et CAMPBELL, 2000; ERRÉCALDE et al., 1998) ainsi que les complexes inorganiques composés du thiosulfate tels $\mathrm{AgS}_{2} \mathrm{O}_{3}$ (FORTIN et CAMPBELL, 2001; HIRIART-BAER et al., 2006) et $\mathrm{CdS}_{2} \mathrm{O}_{3}{ }^{0}$ (BOILY, 2004), en sont de bons exemples.

\subsubsection{Formation d'un complexe ternaire à la surface cellulaire}

Le MLB stipule que la réponse biologique d'un organisme à un métal dépend de la concentration des complexes de surface (M-X-cellule) formés entre le métal et les sites physiologiquement actifs. Ainsi, la formation de complexes de surface ternaire (L-M-X-cellule) pouvant exercer un effet toxique en demeurant à la surface biologique entraîne une déviation au MLB. Dans ces cas, la réponse biologique devient proportionnelle à la concentration de complexe (ML) plutôt qu'à l'ion libre. Par exemple, la toxicité du Cd chez l'algue verte Pseudokirchneriella subcapitata serait augmentée en présence d'un acide aminé, l'alanine, en raison probablement de la formation d'un complexe ternaire (alanine-Cd-X-Cellule) (CAMPBELL et al., 2002).

\subsubsection{Contrôle cinétique de la prise en charge du métal}

Le transport des métaux à l'intérieur des cellules est contrôlé thermodynamiquement d'après le MLB. Le MLB a en effet comme prémisse que l'internalisation des métaux par les systèmes de transport membranaires constitue l'étape lente du processus de prise en charge des métaux. Le transport du métal de la solution vers la membrane et la réaction de complexation/dissociation de surface subséquente se font relativement rapidement comparativement à l'internalisation des métaux dans les cellules. Cela fait en sorte qu'un équilibre peut s'établir entre les espèces métalliques en solution et l'ion libre lié à la surface des cellules. Il s'en suit que si la diffusion des métaux vers la membrane (voir section 4.2.3.1) ou si la liaison des métaux avec le ligand biotique devient l'étape lente du processus (HUDSON, 1998), l'accumulation des métaux est contrôlée cinétiquement (et proportionnelle à la concentration de métal labile), ce qui est en désaccord avec le MLB.

\subsubsection{Transport limité par la cinétique de dissociation du métal}

À notre connaissance, une seule étude a démontré hors de tout doute que la prise en charge d'un métal pouvait être beaucoup plus rapide que la vitesse d'association du métal aux sites physiologiquement actifs. En réalisant des expériences de prise en charge transitoire ainsi que des expériences de type pulse-chase avec le Fe chez l'algue marine Thalassiosira weissflogii, HUDSON et MOREL (1990) ont montré que le taux de formation du complexe de surface était similaire au taux d'internalisation du $\mathrm{Fe}$ et beaucoup plus grand que le taux de dissociation de ce complexe de surface, démontrant sans équivoque un contrôle cinétique de la prise en charge. Il faut noter que ce phénomène est causé essentiellement par la lente cinétique de complexation et de dissociation du Fe. Ainsi, il serait possible que l'on retrouve le même phénomène avec d'autres métaux ayant une cinétique lente comme le Ni (métal essentiel facultatif) et l'aluminium (métal non essentiel), par exemple.

\subsubsection{Prise en charge limitée par la diffusion du métal vers la membrane}

Si le transport des espèces métalliques vers la surface des cellules devient l'étape limitante de la prise en charge, le flux maximal d'internalisation atteignable par les organismes ne pourra dépasser le flux diffusif maximal. Une prise en charge limitée par la diffusion est plus susceptible d'être observée 
en présence de faibles concentrations de métaux, lorsque le gradient de diffusion entre la solution et la surface biologique est faible. La diffusion des espèces chimiques vers les sites d'internalisation des organismes aquatiques peut dépendre de plusieurs facteurs, telles la taille et la charge de l'ion métallique, la taille et la forme de l'organisme et la position de l'organisme par rapport à d'autres (plancton, colonies, biofilms). Pour des cellules sphériques, le transport physique ou le taux de diffusion maximale des espèces métalliques en solution pour une concentration donnée peut être calculé par des équations mathématiques, à partir du rayon des cellules et du coefficient de diffusion du métal (FORTIN et CAMPBELL, 2000; PINHEIRO et VAN LEEUWEN, 2001; WHITFIELD et TURNER, 1979; WILKINSON et BUFFLE, 2004).

Une limite imposée par la diffusion a été suggérée ou démontrée pour plusieurs éléments traces chez des algues marines et d'eau douce. Chez le phytoplancton marin, il existe dans la littérature un nombre considérable d'exemples de flux d'internalisation rapides des métaux qui s'approchent du flux diffusif maximal. En effet, les flux de prise en charge du Zn (SUNDA et HUNTSMAN, 1992), du Fe (HUDSON et MOREL, 1990; SUNDA et HUNTSMAN, 1995a), du $\mathrm{Cu}$ (SUNDA et HUNTSMAN, 1995b), du Mn (seulement pour une espèce) et même du $\mathrm{Cd}$ (par les transporteurs du Mn) (SUNDA et HUNTSMAN, 1996) chez quelques algues marines peuvent représenter une fraction non négligeable du flux maximal calculé dicté par la diffusion des espèces labiles. Ces résultats suggèrent que les flux d'internalisation de ces métaux chez ces espèces phytoplanctoniques marines pourraient être limités par la diffusion des espèces métalliques labiles.

Pour ce qui est des espèces phytoplanctoniques d'eau douce, deux exemples seulement où l'accumulation de métal serait contrôlée par la diffusion (l'un pour un élément essentiel et l'autre pour un élément non essentiel) furent répertoriés dans la littérature. Premièrement, l'algue verte, Chlorella kesslerii, lorsqu'acclimatée à une concentration très faible de $\mathrm{Zn}^{2+}$ de $10^{-11} \mathrm{M}$, pourrait prendre en charge le $\mathrm{Zn}$ (concentrations variant de $10^{-12} \mathrm{M}$ et $10^{-10,7} \mathrm{M}$ ) à une vitesse presque dix fois supérieure au flux maximal calculé prédit par la diffusion du $\mathrm{Zn}^{2+}$ au travers de la phycosphère, suggérant fortement que les complexes labiles $\left(\mathrm{ZnOH}^{+}, \mathrm{ZnHCO}^{3+}\right)$ peuvent contribuer à la prise en charge du $\mathrm{Zn}$ dans ces conditions (HASSLER et WILKINSON, 2003). Deuxièmement, la prise en charge de l'argent augmente en présence de chlorure chez $C$. reinhardtii (FORTIN et CAMPBELL, 2000) pour des concentrations d'argent relativement faibles, mais n'augmente pas chez deux autres espèces d'algues vertes, soit $P$. subcapitata et Chlorella pyrenoidosa (LEE et al., 2004). Ces résultats seraient dus à la prise en charge particulièrement rapide de l'argent chez C. reinhardtii, qui fait en sorte que le transport physique de l'Ag $^{+}$de la solution vers la membrane cellulaire devienne l'étape limitante pour cette espèce et que les chloro-complexes de l'argent contribuent à l'internalisation de l'argent en se dissociant dans la phycosphère.

Il faut garder en tête que cette apparente déviation au MLB (transport des métaux contrôlés par la cinétique) risque bien de n'avoir que peu d'impact dans la prédiction de la toxicité de plusieurs métaux en nature (sauf pour le cas de l'Ag cité plus haut). Les concentrations de métaux ambiantes pouvant mener à des effets toxiques sont habituellement relativement élevées et ces conditions sont peu susceptibles de mener à une diffusion limitante.

4.2.4 Modification de la nature du ligand biotique au cours du temps d'exposition

Le MLB présume aussi que le ligand biotique (ou les sites physiologiquement actifs) ne subit pas de modification durant une courte période d'exposition aux métaux. Cependant, les organismes aquatiques possèdent des mécanismes homéostatiques précis permettant de réguler l'accumulation de certains métaux en fonction du temps et surtout lors d'expositions chroniques aux métaux. En effet, les transporteurs membranaires des métaux sont continuellement recyclés, dégradés et synthétisés à des rythmes qui peuvent être modifiés par les cellules (SLAVEYKOVA et WILKINSON, 2005). Ces transporteurs auraient été très conservés au fil de l'évolution, ce qui pourrait expliquer que la biodisponibilité des métaux dissous est souvent similaire chez un poisson, une daphnie et une algue (PAQUIN et al., 2002a). Par exemple, il est bien connu que les poissons (HOGSTRAND et WOOD, 1995; HOLLIS et al., 1999) et les algues (HARRISON et MOREL, 1986; SUNDA et HUNTSMAN, 1998c) puissent réguler la prise en charge de métaux en modifiant les caractéristiques des sites de liaison (nombre et/ou affinité) sur les branchies ou les membranes cellulaires lors d'exposition à moyen ou long terme.

La régulation par " rétroaction négative " est un des mécanismes cellulaires bien connus dans la littérature, qui permet l'acclimatation des cellules phytoplanctoniques à différentes concentrations de métaux essentiels afin de maximiser la croissance cellulaire. Lélément nutritionnel présent en concentration suffisante dans l'environnement et par conséquent à l'intérieur des cellules algales, inhiberait (d'où le nom " rétroaction négative ") la synthèse de transporteurs membranaires et/ou stimulerait leur dégradation et/ou inhiberait l'activité du transporteur par un complexe intracellulaire ou un métabolite interagissant avec les transporteurs membranaires. À mesure que la concentration de métaux essentiels diminue dans le milieu ainsi que dans les cellules, la synthèse de nouveaux transporteurs est de moins en moins inhibée et est donc stimulée par les cellules (SUNDA et HUNTSMAN, 1986, 1998c). 
Plusieurs études chez les algues démontrent qu’une préexposition (généralement quelques heures suffisent) à des concentrations de métaux essentiels ( $\mathrm{Mn}, \mathrm{Zn}, \mathrm{Fe}, \mathrm{Cu}$ ) permettant une croissance optimale, ou induisant une carence, peuvent mener à une modulation des flux de prise en charge de ces métaux à court terme, cette variation pouvant dépasser un facteur 100 (HARRISON et MOREL, 1986; HASSLER et WILKINSON, 2003; HILL et al., 1996; LAVOIE et al., 2012a; SUNDA et HUNTSMAN, 1992, 1995a, 1995b, 1998a). Ces études comparent généralement la prise en charge à court terme de nutriments chez des organismes ayant été cultivés à des concentrations faibles (diminuant la croissance) ou optimales de nutriments. Les vitesses maximales d'internalisation $\left(V_{\max }\right)$ sont typiquement plus élevées pour les organismes ayant été acclimatés à une plus faible concentration de métaux traces essentiels que pour ceux cultivés en conditions de culture optimales (Figure 2a). Pour la forte majorité des métaux traces testés, les constantes d'affinité pour les transporteurs des nutriments demeurent généralement constantes, indépendamment des conditions de croissance maintenues avant l'expérience de prise en charge.
Toutefois, dans le cas du Zn, la constante d'affinité augmente chez les algues acclimatées aux faibles concentrations de $\mathrm{Zn}$ comparativement à celles acclimatées à des concentrations plus élevées (HASSLER et WILKINSON, 2003; SUNDA et HUNTSMAN, 1992) (Figure $2 b$ ). Ces résultats suggèrent que ce mécanisme de régulation par rétroaction négative des concentrations des métaux intracellulaires est relié de façon primordiale à la synthèse de transporteurs membranaires similaires à ceux présents chez les algues non acclimatés tandis que, pour le $\mathrm{Zn}$, il y aurait aussi induction de différents types de transporteurs ou de changements de l'affinité d'un transporteur donné.

Les algues, comme plusieurs autres organismes vivants, ont évolué vers ce type de régulation homéostatique pour contrôler efficacement l'assimilation des macro et micronutriments à l'intérieur d'un environnement où l'abondance de nutriments varie fortement dans le temps et dans l'espace. Ce type de régulation par rétroaction négative ferait en sorte de réguler la prise en charge à l'état stationnaire des métaux essentiels pour maintenir les quotas intracellulaires de ces métaux les plus près

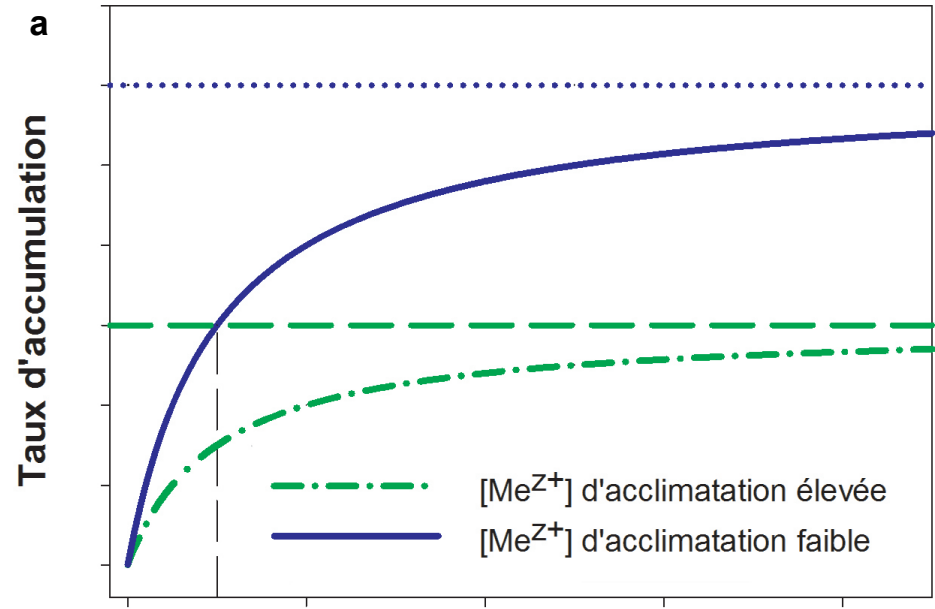

$\left[\mathrm{Me}^{\mathrm{z+}}\right]$

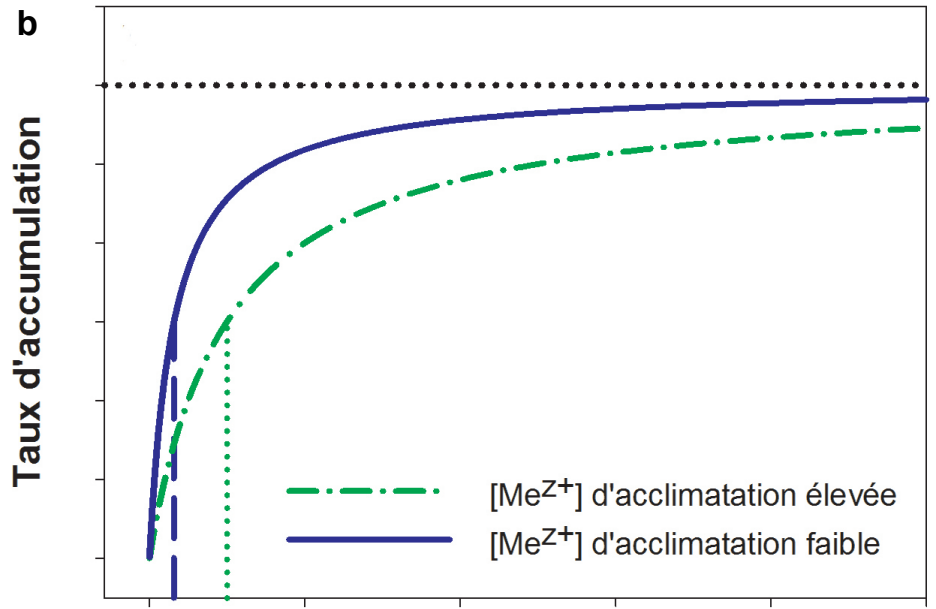

$\left[\mathrm{Me}^{\mathrm{Z+}}\right]$

Figure 2. Exemple de relation entre le taux d'accumulation d'un métal et la concentration de $\mathbf{M}^{\mathrm{z}+}$ pour des expositions à court terme chez une algue hypothétique ayant été pré-acclimatée à une faible (courbe pleine bleu) ou une forte (courbe verte avec tirets et points) concentration de $\mathrm{M}^{\mathrm{z}}$. Les unités sont arbitraires et les courbes modélisées sont présentées sous une échelle linéaire sur les deux axes $x$ et $y$. a) Les algues modulent le taux maximal de transport $\left(V_{m a x}\right)$ en fonction du milieu d'acclimatation, mais ne modifient pas l'affinité du transporteur pour le métal $\left(K_{M}\right)$. Les $V_{m a x}$ sont présentés par les lignes horizontales pointillées bleues et les tirets horizontaux verts chez les algues acclimatées respectivement aux faibles et aux fortes concentrations de métal. $\mathrm{La}\left[\mathrm{M}^{\mathrm{z}}\right]$ où le système de transport est à demi saturé est représentée par des tirets noirs. b) Les algues modifient l'affinité $\left(K_{M}\right)$ du système de transport pour le métal sans modifier le $V_{\text {max }}$. $\mathrm{La}\left[\mathrm{M}^{\mathrm{z}+}\right]$ où le système est à demi saturé par le métal $\left(\left[\mathrm{M}^{\mathrm{z}+}\right]=1 / K_{M}\right)$ est représentée par les tirets bleus et les pointillés verts chez les algues acclimatées respectivement à une faible et une forte concentration de $\mathrm{M}^{\mathrm{t+}}$. Le $V_{\max }$ est représenté par la ligne pointillée noire.

Typical relationship between metal uptake rates and the free ion concentrations for a short-term exposure in a hypothetical alga pre-acclimated to low (solid blue curve) or high (dashed green curve) free metal concentrations ([M $\left.{ }^{+}\right]$). Units are arbitrary and the modeled curves are represented on a linear scale on the $x$ and $y$ axes. a) The algae modulate the maximal uptake rate $\left(V_{\text {max }}\right)$ as a function of the acclimation medium, but do not modify the transporter affinity for the metal $\left(K_{M}\right)$. The $V_{\text {max }}$ are represented by horizontal dotted (blue) and dashed (green) lines in algae acclimated to low and high free metal concentrations respectively. The [ $\left.M^{{ }^{+}}\right]$where the metal transport system is half-saturated is shown with black dashed lines. $b$ ) The algae may control the affinity $\left(K_{M}\right)$ of the metal transport system without modifying $V_{\text {max }}$. The [M $\left.{ }^{k+}\right]$ where the uptake system is half-saturated by the metal $\left(\left[M^{k+}\right]=1 / K_{M}\right)$ is specified by dashed (blue) and dotted (green) lines for the algae preacclimated to low and high free metal concentrations respectively. The $V_{\text {max }}$ is represented with the black dotted line. 
possibles des quotas optimaux pour la croissance. La capacité à synthétiser de transporteurs additionnels est cependant limitée, notamment à cause de l'espace disponible dans la membrane cellulaire (HUDSON et MOREL, 1993). Cela fait en sorte qu'à partir d'une concentration métallique faible critique, la cellule ne pourrait plus être capable de prendre en charge le métal à un rythme suffisant pour permettre la croissance optimale de l'algue (voir exemple avec le Mn dans SUNDA et HUNTSMAN [1998a]). Il est aussi possible que la cellule puisse continuer à synthétiser des transporteurs dans le but de stimuler le taux de prise en charge du métal essentiel même à des concentrations de métaux très faibles où la prise en charge devient limitée par la diffusion des espèces labiles. Dans ce cas, l'accumulation de métaux analogues par les mêmes transporteurs membranaires pourra être stimulée. Si ces métaux analogues peuvent remplacer la fonction de métal essentiel, l'augmentation de la prise en charge pourra être bénéfique pour la croissance de l'algue. Sinon, la cellule aggravera son problème de manque de métaux essentiels, ce qui pourrait conduire à des effets de carence (voir les exemples avec le Zn dans SUNDA et HUNTSMAN [1998b]). Inversement, lorsque la concentration de métaux essentiels devient supérieure à ses capacités de régulation, la cellule ne peut plus dégrader ou désactiver ces transporteurs membranaires et ne régule donc plus l'internalisation de métaux essentiels. Dans ces dernières conditions, la prise en charge de métaux essentiels devient proportionnelle à l'ion libre, conformément au modèle de l'ion libre, à condition que les systèmes de transport métalliques soient loin d'être saturés par le métal libre en solution. Ainsi, vu l'excès de métaux essentiels accumulé par les algues, des effets toxiques peuvent se manifester (SUNDA et HUNTSMAN, 1992, 1998c). Par ailleurs, la prise en charge des métaux non essentiels, étant accumulés par le phytoplancton par un ou des transporteurs de métaux essentiels, sera influencée parfois de façon très importante par les concentrations ambiantes de métaux essentiels, qui moduleront l'activité des transporteurs des métaux essentiels par rétroaction négative (LAVOIE et al., 2012a, 2014; SUNDA et HUNTSMAN, 1998c). Ce rôle interactif des micronutriments essentiels sur la toxicité des métaux par leur modulation du taux de prise en charge maximale des cellules algales n'est pas pris en compte à l'intérieur de la version actuelle du MLB.

\subsubsection{Présence de plusieurs types de systèmes de transport dans la membrane cellulaire}

Le MLB prédit que l'accumulation des métaux se fait par un seul type de transporteur. Cependant, il est maintenant de plus en plus clair qu'une famille de différents ligands biotiques, associée à différents systèmes de transport pouvant transporter un même métal, existe à la surface des organismes (voir section 5 pour plus de détails à ce sujet). Outre les découvertes récentes des séquences génétiques des transporteurs ZIP de différentes affinités chez $C$. reinhardtii, des expériences de cinétique d'accumulation suggèrent la présence de différents types de transporteurs dans le cas du Zn chez le phytoplancton marin (SUNDA et HUNTSMAN, 1992) et d'eau douce (HASSLER et WILKINSON, 2003; LAVOIE et al., 2012a). De façon analogue à une synthèse de transporteurs induite sur une période de temps plus longue (voir section 4.2.4), la prise en charge du $\mathrm{Zn}$ à court terme n'était pas directement proportionnelle à la concentration de $Z$ n libre en solution. Dans ces conditions, on s'attend à obtenir une courbe constituée de deux fonctions hyperboliques décalées qui se recoupent (formant une courbe hyperbolique avec deux plateaux) au lieu d'une simple courbe hyperbolique qui relie l'accumulation des métaux à la concentration de l'ion libre en solution (Figure 3). Cela fait en sorte que la liaison aux sites physiologiquement actifs des métaux sur les membranes algales devient pour une gamme de concentrations métalliques ne saturant pas les transporteurs : $i$ ) reliée de façon linéaire à l'ion libre (sites de transport avec une affinité élevée et une capacité faible pour les métaux), pour la partie linéaire inférieure de la courbe; ii) indépendante de la concentration de l'ion libre, à l'intérieur de la portion de la courbe où il y a saturation des sites de haute affinité; iii) reliée de façon linéaire à l'ion libre (sites de transport avec une affinité faible et une capacité élevée pour les métaux), dans la seconde partie linéaire de la courbe. Les conséquences pratiques de cette contradiction apparente au MLB s'avèrent toutefois peu importantes pour l'application du MLB en nature dans un contexte toxicologique des métaux essentiels et non de nutrition (ou de carence) chez le phytoplancton. En effet, le MLB s'attardera aux concentrations de métaux essentiels pouvant être potentiellement toxiques envers les algues et donc, pour une gamme de concentration de métaux essentiels relativement élevée et possiblement à l'intérieur d'une gamme de concentration étroite, probablement située à l'intérieur de la seconde partie linéaire de la courbe hyperbolique à deux plateaux traitée ci-dessus. À ces fortes concentrations de métaux essentiels (plus grandes que celles pouvant soutenir la croissance maximale), la prise en charge et la toxicité de ces métaux devraient être fonction de la concentration de l'ion libre puisque l'entrée des métaux ne pourrait plus être régulée par les cellules. CAMPBELL (1995) a d'ailleurs recensé plusieurs exemples ( 52 des 59 cas étudiés) où le MLB pouvait s'appliquer chez les éléments traces essentiels, dont le $\mathrm{Zn}$.

\subsubsection{Transport actif}

Les métaux traces seraient pris en charge par transport facilité d'après le MLB, c'est-à-dire que des transporteurs protéiques utilisent le gradient électrochimique transmembranaire comme force motrice et ne nécessitent pas directement d'énergie biochimique (ATP et NADPH). Contrairement à ce que le MLB sous-entend, les algues transporteraient aussi plusieurs métaux essentiels (ex. : Fe, $\mathrm{Cu}$ et $\mathrm{Zn}$ ) grâce à des transporteurs de métaux activés par de l'énergie biochimique (ex. : ATP, NADPH) (voir section 3.1 pour plus de détails à ce sujet) (ANDERSON et MOREL, 1982; WEGER et ESPIE, 2000; XUE et al., 1998). 


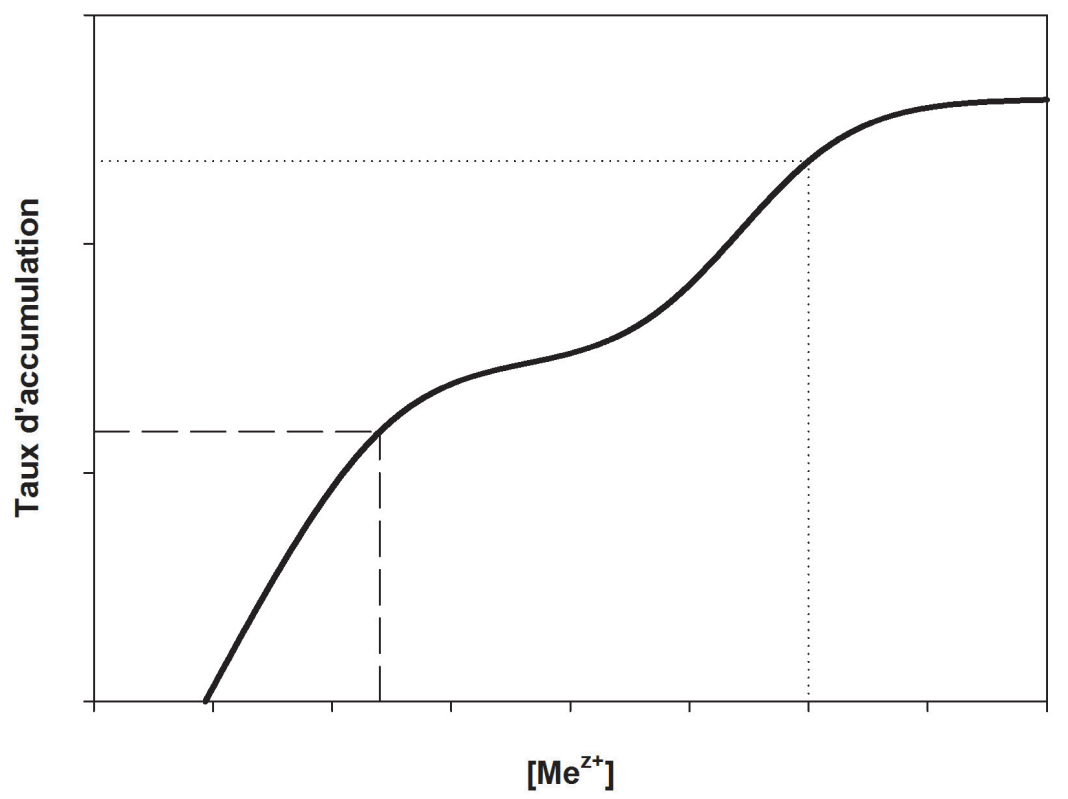

Figure 3. Exemple de relation entre le taux d'accumulation d'un métal par deux systèmes de transport et la concentration de $\mathrm{M}^{\mathrm{z}}$ pour des expositions à court terme chez une algue hypothétique. La courbe modélisée indique la présence de deux systèmes de transport de différentes affinités pour le $\mathbf{M}^{\mathrm{z}}$. Les tirets et les pointillés indiquent respectivement, pour le transporteur de haute et de faible affinité, le point où ces transporteurs sont à demi saturés par le métal (où $\left[\mathrm{M}^{\mathrm{z}+}\right]=1 / K_{M}$ ). Les unités sont arbitraires et une échelle logarithmique est utilisée sur l'axe des $x$ et des $y$ afin de bien visualiser l'ensemble des deux systèmes de transport.

Typical relationship between metal uptake rates via two transport systems and free ion metal concentrations ([M $\left.\left.{ }^{z+}\right]\right)$ for short-term exposures of a hypothetical alga. The modeled curve indicates the presence of two metal transport systems with different affinities for $M^{z+}$. The dashed and dotted lines show for the transporter of high and low affinity respectively, the point where the transporters are half-saturated by metals (at $\left[M^{z^{+}}\right]=1 / K_{M}$ ). Units are arbitrary and a log scale is used on the $x$ and $y$ axes to show the responses of the high and low affinity transporters equally well.

4.2.7 Effets physiologiques complexes du $p H$, du calcium ou d'un mélange de métaux

Certaines variables physicochimiques peuvent affecter la physiologie du phytoplancton et, de façon indirecte, le transport membranaire des métaux et leur toxicité. Ce type de modulation de la prise en charge des métaux ne fait pas partie présentement du MLB. À ce jour, il est relativement peu compris et peu d'études se sont attardées à ce sujet. Quelques exemples seulement ont été répertoriés dans la littérature. Premièrement, une augmentation de la concentration de $\mathrm{Ca}$ inhiberait de façon non compétitive la prise en charge de $\mathrm{Ni}$ (WORMS et WILKINSON, 2007) et de Cd (LAVOIE et al., 2014) pour des expériences à court terme (30-40 min) chez C. reinhardtii, suggérant une modification de la conformation des transporteurs membranaires (modulation de la constante de cinétique d'internalisation, $k_{i n}$ ) par le Ca. Le Ca stimulerait aussi faiblement l'accumulation nette de $\mathrm{Ni}$ de façon significative pour des faibles concentrations de $\mathrm{Ni}$ d'exposition en diminuant notamment le taux d'excrétion du Ni des cellules (WORMS et WILKINSON, 2007). Deuxièmement, le pH inhiberait de façon non compétitive la prise en charge du Cd, du $\mathrm{Mn}$ et de l'U chez $C$. reinhardtii, peut-être à cause de son effet sur la conformation des sites de transport membranaire (modulation du $k_{i n}$ ) (FORTIN et al., 2007; FRANÇOIS et al., 2007). Troisièmement, la toxicité résultante d'un mélange de métaux peut être plus (effets synergiques) ou moins (effets antagonistes) élevée que la somme des effets toxiques de chaque métal pris individuellement, de sorte que l'accumulation des métaux dans un mélange peut être stimulée ou inhibée par des mécanismes cellulaires très peu compris (MEYER et al., 2015; TIPPING et LOFTS, 2015) . Par exemple, l'ajout d'une concentration élevée de $\mathrm{Cu}$ au milieu expérimental peut stimuler la prise en charge de plusieurs métaux lors d'une exposition à court terme chez au moins deux espèces d'algues vertes (CHEN et al., 2010; HASSLER et al., 2004; SLAVEYKOVA et WILKINSON, 2002).

\section{LES MÉTAUX HABITUELLEMENT NON ESSENTIELS : LE CAS DU CADMIUM}

\subsection{Présence et spéciation du cadmium}

Le Cd dissous est retrouvé dans les eaux naturelles sous sa forme ionique stable, $\mathrm{Cd}^{2+}$, mais peut former des complexes avec une variété de ligands inorganiques (ions hydroxyles et carbonates à $\mathrm{pH}>8$ ) et organiques (MOD) formant différentes espèces chimiques. En eau douce, le $\mathrm{Cd}$ forme peu de complexes 
avec les ligands inorganiques et organiques comparativement à plusieurs autres métaux. Ainsi, on le retrouve souvent en grande proportion sous sa forme libre $\mathrm{Cd}^{2+}$. En effet, le pourcentage moyen de Cd dissous total mesuré sous forme libre dans une série de lacs de la région de Rouyn-Noranda serait d'environ 50 (MUELLER et al., 2012) à $70 \%$ (FORTIN et al., 2010). Toutefois, comme pour plusieurs métaux, la tendance du Cd à apparaître sous forme de complexes serait fortement reliée à sa concentration dissoute totale et à la productivité primaire des lacs (présence de ligands de nature biologique) et donc au rapport [métal]:[ligands]. En effet, l'espèce $\mathrm{Cd}^{2+}$ pouvait représenter $80 \%$ du Cd total dissous dans le lac Orta (Suisse) (XUE et SIGG, 1998) de faible productivité biologique tandis qu'elle était seulement de 1 à $9 \%$ dans le lac Greifen (Suisse), fortement eutrophe (KALIS et al., 2006; SIGG et al., 2006b; XUE et SIGG, 1998). Notons aussi que la plus forte proportion de Cd sous forme libre dans le lac Orta que dans le lac Greifen serait aussi en partie reliée à la différence de $\mathrm{pH}$ entre les deux lacs, le lac Orta $(\mathrm{pH}=7,3)$ étant plus acide que le lac Greifen $(\mathrm{pH}=8,0)$.

Plusieurs études ont été réalisées afin de connaître le niveau de contamination en $\mathrm{Cd}$ des écosystèmes d'eau douce. Dans les lacs et les rivières qui ne sont pas contaminés par les activités anthropiques, la concentration en $\mathrm{Cd}$ total dissous est typiquement très faible, soit inférieure à $10^{-10} \mathrm{M}$ (XUE et SIGG, 1998). Toutefois, dans les régions minières de RouynNoranda et de Sudbury, la concentration en Cd dissous dans les lacs les plus contaminés varie entre $9 \cdot 10^{-10} \mathrm{M}$ et $2 \cdot 10^{-8} \mathrm{M}$ (CROTEAU et al., 1998; FORTIN et al., 2010; KRAEMER et al., 2006). Les concentrations de $\mathrm{Cd}$ total dissous dans quelques rivières affectées par des rejets miniers acides dans différentes régions du Québec (Canada) atteignaient $6 \cdot 10^{-8}$ à $2,2 \cdot 10^{-7} \mathrm{M}$ (LEGUAY et al., 2016). Des concentrations élevées en $\mathrm{Cd}$ total dissous furent aussi mesurées dans des rivières en milieu urbain en Inde (JAIN et SHARMA, 2001) $\left(\approx 9 \cdot 10^{-8} \mathrm{M}\right)$ et en France (MORIN et al., 2007) $\left(\approx 8,9 \cdot 10^{-7} \mathrm{M}\right)$. Finalement, des concentrations de $\mathrm{Cd}$ total dissous atteignant $10^{-6} \mathrm{M}$ ont été mesurées dans des eaux souterraines affectées par le drainage minier acide en Chine (SUN et al., 2013). Tout dépendant du niveau de complexation du $\mathrm{Cd}$ dissous, les concentrations en $\mathrm{Cd}^{2+}$ libre dans ces écosystèmes affectés par les activités anthropiques pourraient être relativement élevées.

\subsection{Régulation de l'accumulation des métaux essentiels et impact sur l'accumulation et la toxicité du cadmium}

Les expériences de cinétique de prise en charge du $\mathrm{Cd}$ à court terme (et quelques expériences à long terme) chez diverses espèces phytoplanctoniques suggèrent que ce métal peut être accumulé par les transporteurs de différents micronutriments, soit les transporteurs de Mn (HART et al., 1979; SUNDA et HUNTSMAN, 1996, 1998a), de Zn de haute affinité
(LAVOIE et al., 2012a; SUNDA et HUNTSMAN, 1998a; TÖPPERWIEN et al., 2007a, 2007b) et de Fe(II) (LANE et al., 2008, 2009). Chez la diatomée marine T. pseudonana, il a été démontré que la voie de prise en charge du $\mathrm{Cd}^{2+}$ était très dépendante des concentrations de $\mathrm{Mn}^{2+}$ et surtout de $\mathrm{Zn}^{2+}$ auxquelles les algues avaient été acclimatées (SUNDA et HUNTSMAN, 1996, 1998a). En fait, aux $\left[\mathrm{Zn}^{2+}\right]$ relativement élevées permettant une croissance optimale sans induire d'effets toxiques, le taux de prise en charge $\mathrm{du} \mathrm{Cd}^{2+}\left(\left[\mathrm{Cd}^{2+}\right]\right.$ faible $\left.\approx 10^{-12} \mathrm{M}\right)$ sur une période d'exposition à long terme était très dépendant de la $\left[\mathrm{Mn}^{2+}\right]$. Ce dernier résultat s'expliquait par le fait que le $\mathrm{Cd}^{2+}$ était accumulé presqu'exclusivement par le biais des transporteurs de Mn. Dans ces conditions, le taux de prise en charge du Cd diminuait de façon inversement proportionnel à la $\left[\mathrm{Mn}^{2+}\right]$ à cause surtout de la diminution du flux maximal de prise en charge du $\mathrm{Mn}^{2+}$ par rétroaction négative et aussi de la saturation du système de prise en charge du $\mathrm{Mn}^{2+}$ et de la compétition qui en résulte entre le $\mathrm{Mn}^{2+}$ et le $\mathrm{Cd}^{2+}$ pour la liaison aux sites de prise en charge (SUNDA et HUNTSMAN, 1996). Inversement, aux relativement faibles $\left[\mathrm{Zn}^{2+}\right.$ (inhibant le taux de croissance de T. pseudonana ou étant à la limite inférieure de la gamme de $\left[\mathrm{Zn}^{2+}\right]$ permettant une croissance optimale), le taux de prise en charge du $\mathrm{Cd}^{2+}$ n'était presque pas affecté par la $\left[\mathrm{Mn}^{2+}\right]$. Ceci s'expliquait par le fait que le Cd pénétrait presqu'exclusivement par les transporteurs de $\mathrm{Zn}$ de haute affinité dont la synthèse est stimulée aux faibles $\left[\mathrm{Zn}^{2+}\right]$ (SUNDA et HUNTSMAN, 1998c).

Ainsi, la régulation de la synthèse de transporteurs de métaux essentiels (ex. : du $\mathrm{Zn}$ et du $\mathrm{Mn}$ ) par rétroaction négative en réponse à la variation des concentrations de ces cations essentiels affectera la biodisponibilité $\mathrm{du} \mathrm{Cd}$ et sa toxicité à long terme. La toxicité et la prise en charge du $\mathrm{Cd}$ sont notamment plus importantes pour les cellules ayant synthétisé un plus grand nombre de transporteurs membranaires de $\mathrm{Mn}$ (en condition de forte $\left[\mathrm{Zn}^{2+}\right]$ ) ou de $\mathrm{Zn}$, qui peuvent transporter par inadvertance le Cd (HART et al., 1979; LAVOIE et al., 2012a; LAVOIE et al., 2014; SKOWRONSKI et al., 1988; SUNDA et HUNTSMAN, 1996). Cette situation peut donc se traduire par un effet antagoniste des métaux essentiels sur l'accumulation à long terme et la toxicité du Cd (Figure 4a et b). Cependant, le $\mathrm{Cd}$ pourra aussi à son tour influencer le mécanisme de régulation par rétroaction négative en inhibant la prise en charge de métaux essentiels (ex. : Zn et Mn). Aux fortes concentrations de $\mathrm{Cd}$, le mécanisme de rétroaction négative permettant la régulation de la prise en charge de Mn pourrait être fortement voire complètement inhibé par le $\mathrm{Cd}$ (le $\mathrm{Cd}$ agissant à titre de "leurre " aux sites de régulation par rétroaction négative, faisant croire à la cellule qu'elle a assez accumulé de $\mathrm{Mn}$, même si la croissance cellulaire est en vérité inhibée par une carence en $\mathrm{Mn}$ ) chez T. pseudonana (SUNDA et HUNTSMAN, 1996). Dans ce dernier cas, on pourrait s'attendre à ce que l'effet antagoniste (par rétroaction négative) des métaux essentiels sur l'accumulation ou la toxicité 

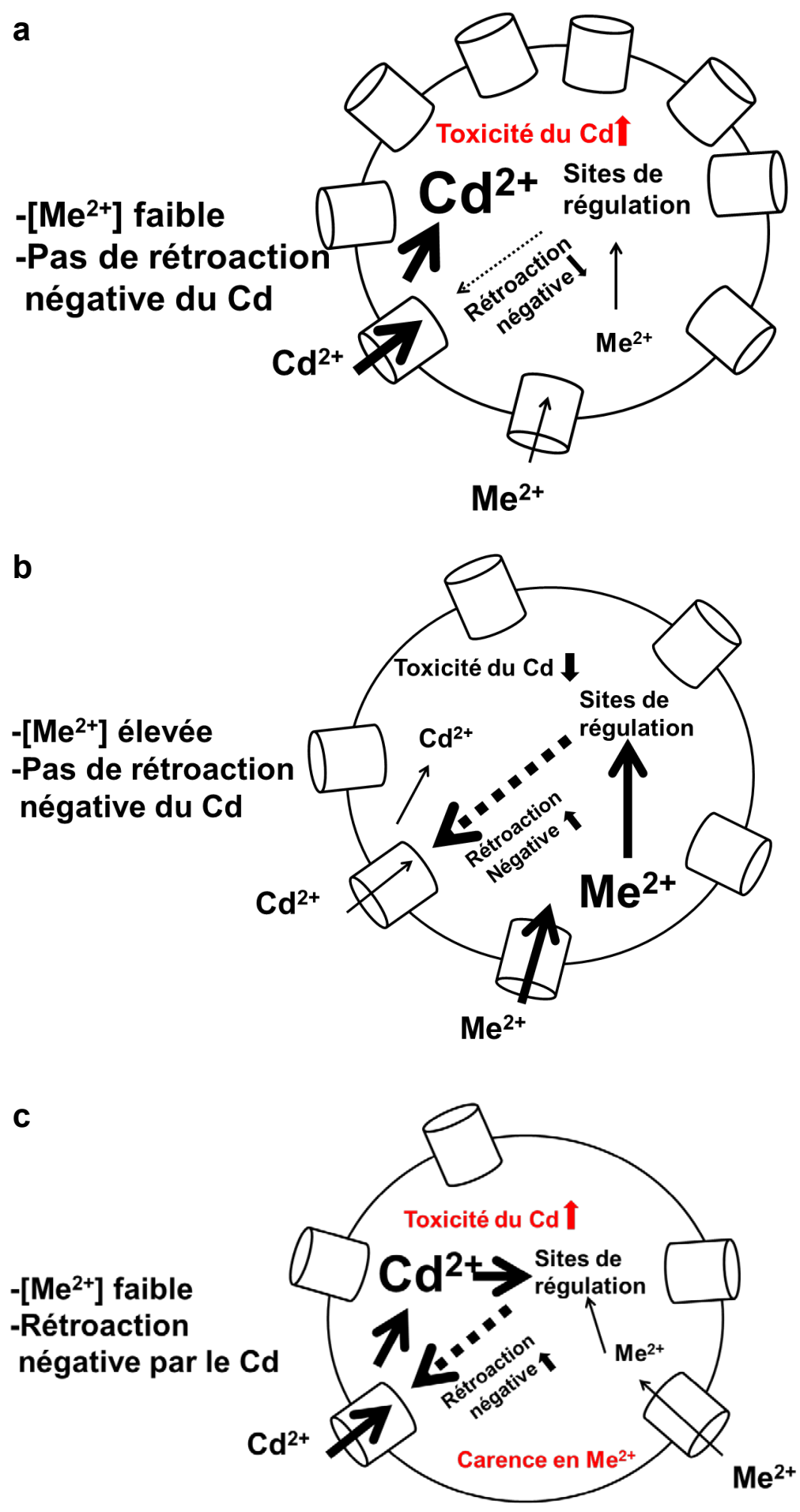

Figure 4. Schéma des interactions physiologiques entre un métal essentiel divalent analogue au $\mathrm{Cd}\left(\mathrm{Me}^{2+}\right)$ et le $\mathrm{Cd}$ du point de vue du système de rétroaction négative régulant la synthèse de transporteurs membranaires de métaux divalents : a) concentrations de métaux essentiels faibles, ce qui stimule la synthèse de transporteurs de métaux divalents par le mécanisme de rétroaction négative. L'accumulation et la toxicité du Cd augmentent par rapport à la figure b; b) concentrations de métaux essentiels élevées inhibant la synthèse de transporteurs de métaux divalents. L'accumulation et la toxicité du Cd diminuent par rapport à la figure a; $\mathrm{c}$ ) le $\mathrm{Cd}$ inhibe la synthèse de transporteurs de métaux divalents, ce qui diminue la capacité de la cellule à augmenter le taux de prise en charge de métaux essentiels en présence de faibles concentrations de métaux essentiels. Cette situation peut mener à une carence en métaux essentiels, ce qui exacerbe la toxicité du Cd. Diagram of the physiological interactions between $C d$ and an essential divalent metal $\left(M^{2+}\right)$ that is a chemical analogue of Cd. The figure shows the negative feedback system that regulates the synthesis of membrane transporters for divalent metals: a) low concentrations of the essential metal, which stimulate the synthesis of divalent metal carriers via the negative feedback mechanism; accumulation and toxicity of $C d$ increase compared to the panel $b ; b$ ) high concentrations of the essential metal, which inhibit the synthesis of divalent metal carrier; accumulation and toxicity of $C d$ decrease relative to the panel a; $c$ ) Cd inhibits the synthesis of divalent metal carriers, which reduces the cell's ability to increase the rate of supply of essential metals in the presence of low concentrations of the essential metals. This can lead to a deficiency in essential metals, which exacerbates Cd toxicity. 
du Cd soit diminué aux plus fortes concentrations de $\mathrm{Cd}$ comparativement aux plus faibles (Figure 4c).

En plus du $\mathrm{Zn}$ et du $\mathrm{Mn}$, le $\mathrm{Fe}(\mathrm{III})$ jouerait un rôle antagoniste sur la prise en charge et la toxicité $\mathrm{du} \mathrm{Cd}$ pour des expositions à long terme $(>4 \mathrm{~h})$ chez certaines espèces phytoplanctoniques (le $\mathrm{Cd}$ pouvant interférer sur les fonctions biochimiques du Fe dans le métabolisme). Chez l'algue marine T. weissflogii, lorsque la concentration de Fe dans le milieu est diminuée, la prise en charge et la toxicité du Cd aqueux seraient exacerbées (FOSTER et MOREL, 1982; HARRISON et MOREL, 1983). En fait, en présence de Cd et d'une forte concentration de Fe (étant suffisante pour permettre la croissance optimale des algues), les cellules accumuleraient des concentrations de Fe plus élevées que celles n'ayant pas été exposées au Cd (témoin). De plus, la diminution de la concentration de $\mathrm{Cd}$ à des niveaux non toxique pour l'algue par un ajout d'EDTA après $56 \mathrm{~h}$ de croissance (tout en maintenant les concentrations libres de l'ensemble des micronutriments constantes), induit une augmentation de la prise en charge de Fe pour atteindre des quotas cellulaires élevées et abolit ou renverse l'effet toxique du $\mathrm{Cd}$ sur la croissance (la croissance des algues reprend de façon similaire au témoin). Ces résultats suggèrent donc que le $\mathrm{Cd}$ interfere avec le métabolisme du $\mathrm{Fe}$, mais que le $\mathrm{Cd}$ ne bloque pas totalement la capacité des cellules à stimuler leur prise en charge de Fe par le mécanisme de rétroaction négative (HARRISON et MOREL, 1983). Chez l'algue d'eau douce $P$. subcapitata, un antagonisme du Fe fut aussi démontré sur la toxicité du Cd lors d'exposition de $96 \mathrm{~h}$ (MALONEY, 2007). En revanche, le Fe(III) ne serait pas reconnu comme un bon inhibiteur de la prise en charge de Cd à court terme, du moins chez $C$. reinhardtii. Chez cette dernière espèce, le $\mathrm{Fe}(\mathrm{III})$ ne jouerait pas de rôle antagoniste sur l'accumulation de $\mathrm{Cd}$ pour une exposition de moins d'une heure (C. HOANG, communication personnelle) ou une exposition de $60 \mathrm{~h}$ (LAVOIE et al., 2012b). Il est possible que le rôle antagoniste du Fe(III) sur la prise en charge et la toxicité $\mathrm{du} \mathrm{Cd}$ chez certaines espèces d'algues unicellulaires soit lié à la synthèse/dégradation de transporteurs de $\mathrm{Fe}(\mathrm{II})$ (pouvant transporter le Cd par inadvertance) comme il a été suggéré chez les plantes supérieures (COHEN et al., 1998; THOMINE et al., 2000) ainsi que chez une espèce de diatomée marine (LANE et al., 2008, 2009).

\subsection{Sensibilité du phytoplancton au cadmium et mécanisme de toxicité}

De nombreux effets toxiques aigus du $\mathrm{Cd}$ ont été documentés dans la littérature chez les plantes et les cellules algales. Ce métal interférerait avec un bon nombre de fonctions cellulaires telles que la division cellulaire (réplication des gènes, altération des microtubules) (VOUTSINAS et al., 1997), les signaux intracellulaires, l'expression des gènes, la réparation des gènes et la photosynthèse. Il perturberait aussi l'intégrité des membranes cellulaires par la peroxydation des lipides (DALCORSO et al., 2008; DECKERT, 2005). Le Cd induirait ces effets toxiques en déplaçant les métaux traces essentiels (ex. : $\mathrm{Ca}, \mathrm{Cu}, \mathrm{Fe}, \mathrm{Zn}$ ) complexés aux protéines et aux enzymes intracellulaires, principalement à cause de sa grande affinité pour les groupements thiols et aussi de ses propriétés ioniques très similaires à celles de certains métaux ( $\mathrm{Ca}$ et $\mathrm{Zn}$ ), et altérerait donc la fonction de ces protéines. Lors de réactions d'oxydoréduction, le $\mathrm{Cu}$ et le Fe libérés mèneraient à la production d'espèces d'oxygène réactives, qui sont très toxiques pour la cellule (PINTO et al., 2003; REA et al., 2004). La sévérité de ces effets toxiques pourrait cependant être atténuée à l'aide de différents mécanismes de détoxication dont la synthèse de peptides détoxifiants (phytochélatines ou protéines de choc thermique) (GERLOFF-ELIAS et al., 2006; HALL et BROWN, 2002; HU et al., 2001; LAVOIE et al., 2009; TORRICELLI et al., 2004), la séquestration du Cd dans des concrétions insolubles de polyphosphate (KOMINE et al., 1996, 2000; RUIZ et al., 2001) ou d'azote/soufre (NASSIRI et al., 1997) ainsi que par l'expulsion du Cd de la cellule (LEE et al., 1996; SUNDA et HUNTSMAN, 1996).

L'étude de la toxicité du Cd surle plan des cibles biochimiques intracellulaires (réplication de gènes, signaux intracellulaires, altération de la fonction de protéines) est souvent réalisée avec des concentrations de Cd plutôt élevées ([Cd] totale > $100 \mu \mathrm{M}$, spéciation non définie) et il est donc difficile de bien cerner les sites intracellulaires potentiels à l'origine de la toxicité du $\mathrm{Cd}$ pour des $\left[\mathrm{Cd}^{2+}\right]$ faibles et représentatives de celles trouvées dans des lacs et rivières contaminés par les activités anthropiques. Les études réalisées à des $\left[\mathrm{Cd}^{2+}\right]$ représentatives de celles retrouvées dans l'environnement et prenant en compte la spéciation du $\mathrm{Cd}$ sont beaucoup plus rares dans la littérature. Le potentiel de croissance cellulaire algal (ou de division cellulaire) serait traditionnellement reconnu comme étant le paramètre de toxicité le plus sensible à la présence $\mathrm{du} \mathrm{Cd}$ chez les microalgues (LE FAUCHEUR et al., 2005; ROSKO et RACHLIN, 1977; SZIVAK et al., 2009; TUKAJ et al., 2007). Des effets toxiques au niveau de la croissance peuvent être décelés à partir de faibles $\left[\mathrm{Cd}^{2+}\right]$, soit près de $10^{-8} \mathrm{M}$ (LAVOIE et al., 2009, 2012b; LE FAUCHEUR et al., 2005). Toutefois, l'efficacité photosynthétique mesurée à l'aide de fluorimètre de type PAM (pulse-amplitude-modulated fluorometry) pourrait être un paramètre de toxicité du Cd de sensibilité comparable au taux de croissance, du moins chez certaines espèces d'algues marines (MIAO et al., 2005).

\subsection{Prédiction de l'accumulation et de la toxicité du cadmium en tenant compte des effets physiologiques des éléments essentiels}

Certaines modifications peuvent être apportées au formalisme mathématique du MLB (présenté à la section 4) 
afin d'étendre et d'améliorer l'applicabilité de ce modèle à des conditions chimiques plus complexes et à la prédiction de la toxicité chronique des métaux dans les écosystèmes d'eau douce. En effet, les études récentes de LAVOIE et al. (2012a, 2012b, 2014) ont cherché à modéliser l'accumulation et la toxicité chronique du $\mathrm{Cd}$ chez l'algue verte $C$. reinhardtii cultivée en présence de différentes concentrations d'éléments essentiels. Ces études ont montré qu'en incorporant l'effet modulateur de cinq éléments traces $(\mathrm{Co}, \mathrm{Cu}, \mathrm{Fe}, \mathrm{Mn}, \mathrm{Zn}$; seuls ou en combinaison) sur la physiologie $\left(V_{\max }\right.$ et $\left.K_{M}\right)$ de trois systèmes de transport membranaire participant à la prise en charge de $\mathrm{Cd}(\mathrm{Cd}-1, \mathrm{Cd}-2$ et $\mathrm{Cd}-3)$, il était possible de prédire adéquatement l'accumulation du $\mathrm{Cd}$ pour des expositions chroniques de $60 \mathrm{~h}$. Toutefois, les effets modulateurs des métaux traces essentiels sur la toxicité chronique $\mathrm{du} \mathrm{Cd}$ étaient plus difficiles à modéliser à cause notamment de la faible sensibilité des concentrations intracellulaires de $\mathrm{Cd}$ à des variations des concentrations de $\mathrm{Cd}^{2+}$ étant toxiques chez C. reinhardtii. Cette situation s'explique par le fait que les concentrations de $\mathrm{Cd}^{2+}$ libre inhibant significativement le taux de croissance de l'algue dans les milieux avec ajout de $\mathrm{Zn}^{2+}$ ou de plusieurs métaux traces en combinaison sont proches de celles qui saturent le système de transport $\mathrm{Cd}-2$. Ainsi, pour une faible variation de la concentration de $\mathrm{Cd}$ intracellulaire inhibant de $20 \%$ le taux de croissance chez C. reinhardtii, une grande gamme de concentrations de $\mathrm{Cd}^{2+}$ est possible et donc l'EC20 modélisée est incertaine (LAVOIE et al., 2014). Ces études récentes indiquent l'importance de comprendre et d'appliquer des éléments de physiologie algale au MLB pour mieux prédire l'accumulation chronique $\mathrm{du} \mathrm{Cd}$. Toutefois, plus de travail est nécessaire afin de bien implémenter dans le MLB les mécanismes modulateurs de la toxicité du Cd chez le phytoplancton en présence de différentes concentrations d'éléments essentiels.

L'approche mathématique relativement simple du MLB a aussi permis dans le passé de bien modéliser l'accumulation à long terme de différents éléments essentiels $(\mathrm{Co}, \mathrm{Cu}, \mathrm{Fe}$, $\mathrm{Mn}, \mathrm{Zn}$ ) chez plusieurs espèces marines de phytoplancton (SUNDA et HUNTSMAN, 1998a, 1998b, 2000). La capacité à modéliser avec confiance l'accumulation du $\mathrm{Cd}$ à l'état stationnaire, étant contrôlé par les effets du $\mathrm{Zn}$ et de $\mathrm{Mn}$ sur les paramètres cinétiques des transporteurs de $\mathrm{Zn}$ et de $\mathrm{Mn}$ chez la diatomée marine T. pseudonana, fut aussi très bien démontrée par SUNDA et HUNTSMAN (1996, 1998). Précisons toutefois qu'à forte $\left[\mathrm{Cd}^{2+}\right]$, où des effets toxiques sur la croissance de cette diatomée apparaissaient (c.-à-d. à $5 \cdot 10^{-9} \mathrm{M} \mathrm{Cd}^{2+}$ ), la modélisation de l'accumulation du Cd à l'état stationnaire devenait plus complexe. Un système exportant le Cd à l'extérieur de la cellule était mis en branle, faisant en sorte de diminuer grandement (de près d'un ordre de grandeur) l'accumulation de Cd mesurée à l'état stationnaire par rapport au Cd intracellulaire modélisé (sans tenir compte de l'efflux de Cd) (SUNDA et HUNTSMAN, 1996). Dans ce cas, la diatomée excrétait le $\mathrm{Cd}$ du milieu intracellulaire, car ce métal inhibait le mécanisme de rétroaction négative du Mn permettant de stimuler le taux d'accumulation de $\mathrm{Mn}$ et de maintenir des concentrations de $\mathrm{Mn}$ intracellulaire adéquates pour le métabolisme en présence de fortes concentrations de $\mathrm{Cd}$ intracellulaire. D'autre part, chez C. reinhardtii, l'accumulation $\mathrm{du} \mathrm{Zn}$ demeure bien régulée même en présence de relativement fortes concentrations de $\mathrm{Cd}^{2+}\left(7 \cdot 10^{-9} \mathrm{M} \mathrm{Cd}^{2+}\right)$, c.-à-d. le $\mathrm{Cd}$ n'inhibe pas ou très peu le mécanisme de rétroaction négative permettant une stimulation des taux d'accumulation du $\mathrm{Zn}$ en présence de Cd (LAVOIE et al., 2012a). On déduit donc intuitivement qu'il y aurait peu d'avantages à évoluer un système indépendant d'efflux du $\mathrm{Cd}$ chez $C$. reinhardtii en présence de $\left[\mathrm{Cd}^{2+}\right]<7 \cdot 10^{-9} \mathrm{M}$. Nos résultats n'excluent cependant pas la possibilité qu'un tel système d'efflux existe chez $C$. reinhardtii et soit impliqué dans la détoxication $\mathrm{du} \mathrm{Cd}$ à plus forte $\left[\mathrm{Cd}^{2+}\right]$. En plus d'une modulation potentielle de l'efflux de $\mathrm{Cd}$ chez le phytoplancton marin, il a été démontré que l'algue verte d'eau douce $P$. subcapitata peut réduire grandement le taux d'accumulation du $\mathrm{Cd}$ sur une période de temps $<24 \mathrm{~h}$ en régulant à la baisse le transport du Cd dans les cellules (ERRÉCALDE et CAMPBELL, 2000; PAQUET et al., 2015). Toutefois, après $24 \mathrm{~h}$, les effets de l'accumulation et la toxicité du Cd sur le taux de croissance de l'algue pour une concentration dissoute de $\mathrm{Cd}^{2+}$ donnée pouvaient s'accentuer, indiquant que l'effet toxique du Cd internalisé/adsorbé pouvait se faire ressentir à retardement. Il est aussi possible que cet effet toxique à retardement du $\mathrm{Cd}$ soit dû, du moins en partie, à un changement des sites cellulaires de réponse toxique du $\mathrm{Cd}$ au cours du temps, tel que suggéré par l'étude récente de DUVAL et al. (2015) qui ont modélisé la dynamique de la toxicité du Cd chez P. subcapitata au cours d'une période de $96 \mathrm{~h}$ d'exposition. Ces auteurs ont montré qu'avant $48 \mathrm{~h}$ d'exposition, la toxicité $\mathrm{du} \mathrm{Cd}$ était davantage reliée au $\mathrm{Cd}$ intracellulaire tandis qu'après $48 \mathrm{~h}$, la dynamique des effets toxiques du $\mathrm{Cd}$ ne pouvait être modélisée qu'en prenant en considération le $\mathrm{Cd}$ adsorbé autour des cellules, indiquant un changement des sites cellulaires sensibles visés par le Cd au cours du temps.

\section{CONCLUSION}

Les progrès scientifiques réalisés au cours des deux dernières décennies ont permis d'un côté de mettre en lumière plusieurs limites du MLB. Il est vrai que pour plusieurs de ces cas d'exception au MLB (ex. : contrôle cinétique de la prise en charge, transport passif de complexes lipophiles), le formalisme mathématique de ce modèle pourra difficilement être étendu pour bien prédire la toxicité des métaux. Toutefois, ces exceptions au MLB seront rarement observées dans les milieux naturels d'eau douce. D'autre part, dans plusieurs autres cas où les prémisses du MLB ne peuvent s'appliquer, 
les connaissances acquises récemment sur les mécanismes physiologiques des cellules algales qui modulent d'une façon complexe l'accumulation et la toxicité des métaux offrent la possibilité de raffiner la version actuelle du MLB afin de monter un modèle capable de mieux tenir compte de la physiologie des organismes. Même si un tel MLB "physiologique " avait une portée moins universelle et un peu plus spécifique aux milieux étudiés que la présente version du MLB, l'inclusion de paramètres physiologiques dans le MLB a le potentiel d'améliorer les prédictions de la toxicité chronique des métaux en milieu aquatique. Par exemple, la caractérisation des effets de plusieurs facteurs physicochimiques clés chez quelques espèces représentatives du milieu naturel pourrait être réalisée afin de mieux modéliser et prédire les effets toxiques des métaux dans des conditions données. Le modèle pourrait alors être utilisé pour aider à générer des courbes SSD (species sensitivity distribution) pour les gestionnaires du risque.

Nous espérons que la publication de cette revue de littérature incluant les dernières avancées scientifiques des chimistes del'environnement, des physiologistes, des biologistes moléculaires et des biochimistes à propos de la biodisponibilité des métaux contribuera à rassembler les visions complémentaires de différents spécialistes vers un projet commun ambitieux, soit le développement d'un MLB capable de prédire adéquatement la toxicité des métaux dissous dans l'environnement. Mentionnons toutefois que l'élaboration d'un MLB applicable directement en nature nécessitera plusieurs années de recherche en écotoxicologie. Il reste notamment à déterminer l'importance des réactions physiologiques algales aux cations essentiels/non essentiels chez différentes espèces d'algues en fonction d'une myriade de paramètres physicochimiques (température, lumière, combinaisons de métaux non essentiels, etc.). Cette tâche en l'apparence monumentale pourrait être facilitée par l'avènement de nouvelles approches dites "omiques " (génomiques, transcriptomiques, protéonomiques, et métagénomiques) permettant de caractériser la réponse physiologique de communautés d'algues en milieu naturel à la présence de métaux et de traiter et d'intégrer un grand nombre de données simultanément (BREMBU et al., 2011; HERING, 2009; HUTCHINS et al., 2010; JAMERS et al., 2009; MIGEON et al., 2010; SIMON et al., 2011). Le développement d'un MLB capable de prédire adéquatement la toxicité des métaux en milieu naturel devra aussi bénéficier de nouvelles techniques d'analyse permettant de mesurer d'une façon plus sensible et spécifique la spéciation des métaux en milieu naturel (HERING, 2009; TERCIER-WAEBER et al., 2005, 2012). Finalement, l'intégration des nombreux facteurs influant sur l'accumulation et la toxicité des métaux en milieu naturel (ex. : effets toxiques synergiques ou antagonistes pour des mélanges de métaux ainsi que l'influence potentielle de la température, de l'irradiance et de la photopériode sur la toxicité du Cd) dans le MLB nécessitera l'utilisation de modèles mathématiques de plus en plus complexes et donc, la collaboration des écotoxicologistes avec des spécialistes en modélisation.

Même si encore beaucoup de recherches se doivent d'être réalisées et qu'il nous soit aujourd'hui souvent impossible de prédire adéquatement la toxicité chronique des métaux dans des écosystèmes aquatiques complexes, les travaux scientifiques en cours dans le domaine de l'écotoxicologie des métaux devraient être vus comme des efforts afin d'étendre l'applicabilité du MLB en nature. Cet objectif ne peut être réalisé qu'avec une vision scientifique optimiste, constructive et créative du MLB aux frontières de l'inconnu. Comme le niveau des connaissances dans plusieurs disciplines scientifiques (chimie, physiologie, toxicologie) progresse rapidement, nous croyons que l'objectif d'un MLB capable de réaliser des prédictions fiables à l'intérieur d'une gamme de différents milieux naturels complexes pourrait bien être à notre portée.

\section{REMERCIEMENTS}

M. Lavoie a obtenu une bourse de recherche doctorale et postdoctorale du Fonds de recherche du Québec - Nature et technologies. C. Fortin et P. G. C. Campbell sont appuyés financièrement par le programme de Chaires de Recherche du Canada.

\section{RÉFÉRENCES BIBLIOGRAPHIQUES}

ALLEN A.E., J. LAROCHE, U. MAHESWARI, M. LOMMER, N. SCHAUER, P.J. LOPEZ, G. FINAZZI, A.R. FERNI et C. BOWLER (2008). Whole-cell response of the pennate diatom Phaeodactylum tricornutum to iron starvation. Proc. Natl. Acad. Sci. (USA), 105, 10438-10443.

ANDERSON M.A. et F.M.M. MOREL (1982). Influence of aqueous iron chemistry on uptake of iron by the coastal diatom Thalassiosira weissflogii. Limnol. Oceanogr., 27, 789813.

ARGÜELLO J.M., E. EREN et M. GONZÁLEZGUERRERO (2007). The structure and function of heavy metal transport P1B-ATPases. BioMetals, 20, 233-248.

BIRD D.F. et J. KALFF (1987). Algal phagotrophy: Regulating factors and importance relative to photosynthesis in Dinobryon (Chrysophyceae). Limnol. Oceanogr., 32, 277 284. 
BLABY-HAAS C.E. et S.S. MERCHANT (2012). The ins and outs of algal metal transport. Biochim. Biophys. Acta - Mol. Cell Res., 1823, 1531-1552.

BOILY F. (2004). Mécanismes de prise en charge et toxicité du cadmium en présence de thiosulfate chez une algue verte, Chlamydomonas reinhardtii. Thèse de MSc, Institut national de la recherche scientifique, Québec, QC, Canada,124 p.

BOULLEMANT A., M. LAVOIE, C. FORTIN et P.G.C. CAMPBELL (2009). Uptake of hydrophobic metal complexes by three freshwater algae: Unexpected influence of pH. Environ. Sci. Technol., 43, 3308-3314.

BREMBU T., M. JORSTAD, P. WINGE, K.C. VALLE et A.M. BONES (2011). Genome-wide profiling of responses to cadmium in the diatom Phaeodactylum tricornutum. Environ. Sci. Technol., 45, 7640-7647.

BUDAC D. et P. WAN (1992). Photodecarboxylation: mechanism and synthetic utility. J. Photoch. Photobiol. A, 67, 135-166.

CAMPBELL P.G.C. (1995). Interactions between trace metals and aquatic organisms: A critique of the free-ion activity model. Dans : Metal Speciation and Bioavailability in Aquatic Systems. TESSIER A. et D.R. TURNER (Éditeurs), John Wiley \& Sons, New York, NY, États-Unis, pp. 45102.

CAMPBELL P.G.C. et C. FORTIN (2013). Biotic Ligand Model. Dans : Encyclopedia of Aquatic Ecotoxicology. FÉRARD J-F B.C. (Éditeur), Springer, Dordrecht, PaysBas, p. 237.

CAMPBELL P.G.C., O. ERRÉCALDE, C. FORTIN, V.P. HIRIART-BAER et B. VIGNEAULT (2002). Metal bioavailability to phytoplankton - Applicability of the biotic ligand model. Comp. Biochem. Physiol. C, 133, 189206.

CHEN Z., L. ZHU et K.J. WILKINSON (2010). Validation of the biotic ligand model in metal mixtures: Bioaccumulation of lead and copper. Environ. Sci. Technol., 44, 3580-3586.

COHEN C.K., T.C. FOX, D.F. GARVIN et L.V. KOCHIAN (1998). The role of iron-deficiency stress responses in stimulating heavy-metal transport in plants. Plant Physiol., 116, 1063-1072.
CRÉMAZY A., S. LECLAIR, K.K. MUELLER, B. VIGNEAULT, P.G.C. CAMPBELL et C. FORTIN (2015). Development of an in situ ion-exchange technique for the determination of free $\mathrm{Cd}, \mathrm{Co}, \mathrm{Ni}$, and $\mathrm{Zn}$ concentrations in freshwaters. Aquat. Geochem., 21, 259279.

CROTEAU M.N., L. HARE et A. TESSIER (1998). Refining and testing a trace metal biomonitor (Chaoborus) in highly acidic lakes. Environ. Sci. Technol., 32, 1348-1353.

DALCORSO G., S. FARINATI, S. MAISTRI et A. FURINI (2008). How plants cope with cadmium: Staking all on metabolism and gene expression. J. Integr. Plant Biol., 50, 1268-1280.

DE SCHAMPHELAERE K.A.C. et C.R. JANSSEN (2004). Development and field validation of a biotic ligand model predicting chronic copper toxicity to Daphnia magna. Environ. Toxicol. Chem., 23, 1365-1375.

DE SCHAMPHELAERE K.A.C. et C.R. JANSSEN (2006). Bioavailability models for predicting copper toxicity to freshwater green microalgae as a function of water chemistry. Environ. Sci. Technol., 40, 4514-4522.

DE SCHAMPHELAERE K.A.C., J.L. STAUBER, K.L. WILDE, S.J. MARKICH, P.L. BROWN, N.M. FRANKLIN, N.M. CREIGHTON et C.R. JANSSEN (2005). Toward a biotic ligand model for freshwater green algae: Surface-bound and internal copper are better predictors of toxicity than free $\mathrm{Cu}^{2+}$ ion activity when pH is varied. Environ. Sci. Technol., 39, 2067-2072.

DECKERT J. (2005). Cadmium toxicity in plants: Is there any analogy to its carcinogenic effect in mammalian cells? BioMetals, 18, 475-481.

DELEEBEECK N.M.E., F. DE LAENDER, V.A. CHEPURNOV, W. VYVERMAN, C.R. JANSSEN et K.A.C. DE SCHAMPHELAERE (2009a). A single bioavailability model can accurately predict $\mathrm{Ni}$ toxicity to green microalgae in soft and hard surface waters. Water Res., 43, 1935-1947.

DELEEBEECK N.M.E., K.A.C. DE SCHAMPHELAERE et C.R. JANSSEN (2009b). Effects of $\mathrm{Mg}^{2+}$ and $\mathrm{H}^{+}$ on the toxicity of $\mathrm{Ni}^{2+}$ to the unicellular green alga Pseudokirchneriella subcapitata: Model development and validation with surface waters. Sci. Total Environ., 407, 1901-1914. 
DI TORO D.M., H.E. ALLEN, H.L. BERGMAN, J.S. MEYER, P.R. PAQUIN et R.C. SANTORE (2001). Biotic ligand model of the acute toxicity of metals. 1. Technical basis. Environ. Toxicol. Chem., 20, 2383-2396.

DUVAL J.F.L., N. PAQUET, M. LAVOIE et C. FORTIN (2015). Dynamics of metal partitioning at the cell-solution interface: Implications for toxicity assessment under growthinhibiting conditions. Environ. Sci. Technol., 49, 6625-6636.

ERRÉCALDE O., M. SEIDL et P.G.C. CAMPBELL (1998). Influence of a low molecular weight metabolite (citrate) on the toxicity of cadmium and zinc to the unicellular green alga Selenastrum capricornutum: An exception to the freeion model. Water Res., 32, 419-429.

ERRÉCALDE O. et P.G.C. CAMPBELL (2000). Cadmium and zinc bioavailability to Selenastrum capricornutum (Chlorophyceae): Accidental metal uptake and toxicity in the presence of citrate. J. Phycol., 36, 473-483.

EUROPEAN COMMISSION (2011). Technical guidance for deriving environmental quality standards. Guidance Document No 27, Common Implementation Strategy for the Water Framework Directive, European Commission, Bruxelles, Belgique, 204 p.

FINKEL Z.V., A. QUIGG, J.A. RAVEN, J.R. REINFELDER, O.E. SCHOFIELD et P.G. FALKOWSKI (2006). Irradiance and the elemental stoichiometry of marine phytoplankton. Limnol. Oceanogr., 51, 2690-2701.

FLORENCE T.M., H.K.J. POWELL, J.L. STAUBER et R.M. TOWN (1992). Toxicity of lipid-soluble copper(II) complexes to the marine diatom Nitzschia closterium: Amelioration by humic substances. Water Res., 26, $1187-$ 1193.

FORTIN C. et P.G.C. CAMPBELL (2000). Silver uptake by the green alga Chlamydomonas reinhardtii in relation to chemical speciation: Influence of chloride. Environ. Toxicol. Chem., 19, 2769-2778.

FORTIN C. et P.G.C. CAMPBELL (2001). Thiosulfate enhances silver uptake by a green alga: Role of anion transporters in metal uptake. Environ. Sci. Technol., 35, 2214-2218.

FORTIN C., F.H. DENISON et J. GARNIER-LAPLACE (2007). Metal-phytoplankton interactions: Modeling the effect of competing ions $\left(\mathrm{H}^{+}, \mathrm{Ca}^{2+}\right.$, and $\left.\mathrm{Mg}^{2+}\right)$ on uranium uptake. Environ. Toxicol. Chem., 26, 242-248.
FORTIN C., Y. COUILLARD, B. VIGNEAULT et P.G.C. CAMPBELL (2010). Determination of free Cd, Cu and $\mathrm{Zn}$ concentrations in lake waters by in situ diffusion followed by column equilibration ion-exchange. Aquat. Geochem., 16, 151-172.

FOSTER P.L. et F.M.M. MOREL (1982). Reversal of cadmium toxicity in a diatom: An interaction between cadmium activity and iron. Limnol. Oceanogr., 27, 745-752.

FRANÇOIS L., C. FORTIN et P.G.C. CAMPBELL (2007). $\mathrm{pH}$ modulates transport rates of manganese and cadmium in the green alga Chlamydomonas reinhardtii through noncompetitive interactions: Implications for an algal BLM. Aquat. Toxicol., 84, 123-132.

GERLOFF-ELIAS A., D. BARUA, A. MÖLICH et E. SPIJKERMAN (2006). Temperature- and $\mathrm{pH}$ dependent accumulation of heat-shock proteins in the acidophilic green alga Chlamydomonas acidophila. FEMS Microbiol. Ecol., 56, 345-354.

HALL J.L. et L.E. WILLIAMS (2003). Transition metal transporters in plants. J. Exp. Bot., 54, 2601-2613.

HALL M.J. et M.T. BROWN (2002). Copper and manganese influence the uptake of cadmium in marine macroalgae. Bull. Environ. Contam. Toxicol., 68, 49-55.

HANIKENNE M., U. KRÄMER, V. DEMOULIN et D. BAURAIN (2005). A comparative inventory of metal transporters in the green alga Chlamydomonas reinhardtii and the red alga Cyanidioschizon merolae. Plant Physiol., 137, 428-446.

HARRISON G.I. et F.M.M. MOREL (1983). Antagonism between cadmium and iron in the marine diatom Thalassiosira weissflogii. J. Phycol., 19, 495-507.

HARRISON G.I. et F.M.M. MOREL (1986). Response of the marine diatom Thalassiosira weissflogii to iron stress. Limnol. Oceanogr., 31, 989-997.

HART B.A., P.E. BERTRAM et B.D. SCAIFE (1979). Cadmium transport by Chlorella pyrenoidosa. Environ. Res., $18,327-335$.

HASSLER C.S. et K.J. WILKINSON (2003). Failure of the biotic ligand and free-ion activity models to explain zinc bioaccumulation by Chlorella kesslerii. Environ. Toxicol. Chem., 22, 620-626. 
HASSLER C.S., V.I. SLAVEYKOVA et K.J. WILKINSON (2004). Some fundamental (and often overlooked) considerations underlying the free ion activity and biotic ligand models. Environ. Toxicol. Chem., 23, 283-291.

HEIJERICK D., K. DE SCHAMPHELAERE et C.R. JANSSEN (2002a). Biotic ligand model development predicting $\mathrm{Zn}$ toxicity to the alga Pseudokirchneriella subcapitata: Possibilities and limitations. Comp. Biochem. Physiol. C, 133, 207.

HEIJERICK D.G., K.A.C. DE SCHAMPHELAERE et C.R. JANSSEN (2002b). Predicting acute zinc toxicity for Daphnia magna as a function of key water chemistry characteristics: Development and validation of a biotic ligand model. Environ. Toxicol. Chem., 21, 1309-1315.

HERBIK A., C. BOLLING et T.J. BUCKHOUT (2002). The involvement of a multicopper oxidase in iron uptake by the green algae Chlamydomonas reinhardtii. Plant Physiol., 130, 2039-2048.

HERING J.G. (2009). Metal speciation and bioavailability: Revisiting the "big questions". Environ. Chem., 6, 290293.

HILL K.L., R. HASSETT, D. KOSMAN et S. MERCHANT (1996). Regulated copper uptake in Chlamydomonas reinhardtii in response to copper availability. Plant Physiol., 112, 697-704.

HIRIART-BAER V.P., C. FORTIN, D.Y. LEE et P.G.C. CAMPBELL (2006). Toxicity of silver to two freshwater algae, Chlamydomonas reinhardtii and Pseudokirchneriella subcapitata, grown under continuous culture conditions: Influence of thiosulphate. Aquat. Toxicol., 78, 136-148.

HO T.Y., A. QUIGG, Z.V. FINKEL, A.J. MILLIGAN, K. WYMAN, P.G. FALKOWSKI et F.M.M. MOREL (2003). The elemental composition of some marine phytoplankton. J. Phycol., 39, 1145-1159.

HOGSTRAND C. et C.M. WOOD (1995). Mechanisms for zinc acclimation in freshwater rainbow trout. Mar. Environ. Res., 39, 131-135.

HOLLIS L., J.C. MCGEER, D.G. MCDONALD et C.M. WOOD (1999). Cadmium accumulation, gill Cd binding, acclimation, and physiological effects during long term sublethal $\mathrm{Cd}$ exposure in rainbow trout. Aquat. Toxicol., 46, 101-119.
HOPKINSON B.M. et F.M.M. MOREL (2009). The role of siderophores in iron acquisition by photosynthetic marine microorganisms. BioMetals, 22, 659-669.

HU S., K.W.K. LAU et M. WU (2001). Cadmium sequestration in Chlamydomonas reinhardtii. Plant Sci., 161, 987-996.

HUDSON R.J.M. (1998). Which aqueous species control the rates of trace metal uptake by aquatic biota? Observations and predictions of non-equilibrium effects. Sci. Total Environ., 219, 95-115.

HUDSON R.J.M. et F.M.M. MOREL (1990). Iron transport in marine phytoplankton - Kinetics of cellular and medium coordination reactions. Limnol. Oceanogr., 35, 1002-1020.

HUDSON R.J.M. et F.M.M. MOREL (1993). Trace metal transport by marine microorganisms: implications of metal coordination kinetics. Deep-Sea Res., 40, 129-150.

HUTCHINS C.M., D.F. SIMON, W. ZERGES et K.J. WILKINSON (2010). Transcriptomic signatures in Chlamydomonas reinhardtii as $\mathrm{Cd}$ biomarkers in metal mixtures. Aquat. Toxicol., 100, 120-127.

JAIN C.K. et M.K. SHARMA (2001). Distribution of trace metals in the Hindon River system, India. J. Hydrol., 253, 81-90.

JAMERS A., R. BLUST et W. DE COEN (2009). Omics in algae: Paving the way for a systems biological understanding of algal stress phenomena? Aquat. Toxicol., 92, 114-121.

KALIS E.J.J., L. WENG, F. DOUSMA, E.J.M. TEMMINGHOFF et W.H. VAN RIEMSDIJK (2006). Measuring free metal ion concentrations in situ in natural waters using the Donnan Membrane Technique. Environ. Sci. Technol., 40, 955-961.

KIM B.E., T. NEVITT et D.J. THIELE (2008). Mechanisms for copper acquisition, distribution and regulation. Nature Chem. Biol., 4, 176-185.

KNAUER K., T. JABUSCH et L. SIGG (1999). Manganese uptake and $\mathrm{Mn}(\mathrm{II})$ oxidation by the alga Scenedesmus subspicatus. Aquat. Sci., 61, 44-58.

KOMINE Y., H. PARK, G.R. WOLFE et J.K. HOOBER (1996). Secretory granules in the cytoplasm of a wall-less mutant of Chlamydomonas reinhardtii contain processed light-harvesting complex apoproteins and HSP70. J. Photoch. Photobiol. B, 36, 301-306. 
KOMINE Y., L.L. EGGINK, H. PARK et J.K. HOOBER (2000). Vacuolar granules in Chlamydomonas reinhardtii: Polyphosphate and a $70-\mathrm{kDa}$ polypeptide as major components. Planta, 210, 897-905.

KRAEMER L.D., P.G.C. CAMPBELL, L. HARE et J.-C. AUCLAIR (2006). A field study examining the relative importance of food and water as sources of cadmium for juvenile yellow perch (Perca flavescens). Can. J. Fish. Aquat. Sci., 63, 549-557.

KRÄMER U., I.N. TALKE et M. HANIKENNE (2007). Transition metal transport. FEBS Lett., 581, 2263-2272.

KUSTKA A.B., A.E. ALLEN et F.M.M. MOREL (2007). Sequence analysis and transcriptional regulation of iron acquisition genes in two marine diatoms. J. Phycol., 43, 715-729.

LA FONTAINE S., J.M. QUINN, S.S. NAKAMOTO, M. DUDLEY PAGE, V. GÖHRE, J.L. MOSELEY, J. KROPAT et S. MERCHANT (2002). Copper-dependent iron assimilation pathway in the model photosynthetic eukaryote Chlamydomonas reinhardtii. Eukaryotic Cell, 1, 736-757.

LANE E.S., K. JANG, J.T. CULLEN et M.T. MALDONADO (2008). The interaction between inorganic iron and cadmium uptake in the marine diatom Thalassiosira oceanica. Limnol. Oceanogr., 53, 1784-1789.

LANE E.S., D.M. SEMENIUK, R.F. STRZEPEK, J.T. CULLEN et M.T. MALDONADO (2009). Effects of iron limitation on intracellular cadmium of cultured phytoplankton: Implications for surface dissolved cadmium to phosphate ratios. Mar. Chem., 115, 155-162.

LAVOIE M., S. LE FAUCHEUR, C. FORTIN et P.G.C. CAMPBELL (2009). Cadmium detoxification strategies in two phytoplankton species: Metal binding by newly synthesized thiolated peptides and metal sequestration in granules. Aquat. Toxicol., 92, 65-75.

LAVOIE M., P.G.C. CAMPBELL et C. FORTIN (2012a). Extending the biotic ligand model to account for positive and negative feedback interactions between cadmium and zinc in a freshwater alga. Environ. Sci. Technol., 46, 1212912136.

LAVOIE M., C. FORTIN et P.G.C. CAMPBELL (2012b). Influence of essential elements on cadmium uptake and toxicity in a unicellular green alga: The protective effect of trace zinc and cobalt concentrations. Environ. Toxicol. Chem., 31, 1445-1452.
LAVOIE M., S. LE FAUCHEUR, A. BOULLEMANT, C. FORTIN et P.G.C. CAMPBELL (2012c). The influence of $\mathrm{pH}$ on algal cell membrane permeability and its implications for the uptake of lipophilic metal complexes. J. Phycol., 48, 293-302.

LAVOIE M., P.G.C. CAMPBELL et C. FORTIN (2014). Predicting cadmium accumulation and toxicity in a green alga in the presence of varying essential element concentrations using a Biotic Ligand Model. Environ. Sci. Technol., 48, 1222-1229.

LE FAUCHEUR S., R. BEHRA et L. SIGG (2005). Phytochelatin induction, cadmium accumulation, and algal sensitivity to free cadmium ion in Scenedesmus vacuolatus. Environ. Toxicol. Chem., 24, 1731-1737.

LEAL M.F.C. et C.M.G. VAN DEN BERG (1998). Evidence for strong copper(I) complexation by organic ligands in seawater. Aquat. Geochem., 4, 49-75.

LEE D.Y., C. FORTIN et P.G.C. CAMPBELL (2004). Influence of chloride on silver uptake by two green algae, Pseudokirchneriella subcapitata and Chlorella pyrenoidosa. Environ. Toxicol. Chem., 23, 1012-1018.

LEE J.G., B.A. AHNER et F.M.M. MOREL (1996). Export of cadmium and phytochelatin by the marine diatom Thalassiosira weissflogii. Environ. Sci. Technol., 30, 18141821.

LEE Y. et B.M. TEBO (1994). Cobalt(II) oxidation by the marine manganese(II)-oxidizing Bacillus sp. strain SG-1. Appl. Environ. Microb., 60, 2949-2957.

LEGUAY S., I. LAVOIE, J. LEVY et C. FORTIN (2016) Using biofilms for monitoring metal contamination in lotic ecosystems: the protective effects of hardness and $\mathrm{pH}$ on metal bioaccumulation. Environ. Toxicol. Chem. (sous presse). DOI: 10.1002/etc.3292

LUOMA S.N. et P.S. RAINBOW (2008). Metal contamination in aquatic environments: Science and lateral management. Cambridge University Press, New York, NY, États-Unis, $588 \mathrm{p}$.

MALONEY F. (2007). Influence de paramètres physicochimiques (dureté, pH et présence d'un agent chelateur, l'EDTA) sur la réponse toxique au cadmium de l'algue verte d'eau douce, Pseudokirchneriella subcapitata. Thèse de MSc, Institut national de la recherche scientifique, Québec, QC, Canada, 118 p. 
MASON R.P., J.R. REINFELDER et F.M.M. MOREL (1996). Uptake, toxicity, and trophic transfer of mercury in a coastal diatom. Environ. Sci. Technol., 30, 1835-1845.

MERCHANTS.S., M.D.ALLEN, J.KROPAT, J.L.MOSELEY, J.C. LONG, S. TOTTEY et A.M. TERAUCHI (2006). Between a rock and a hard place: Trace element nutrition in Chlamydomonas. BBA-Mol. Cell Res., 1763, 578-594.

MEYER J.S., K.J. FARLEY et E.R. GARMAN (2015). Metal mixture modeling evaluation project: 1. Background. Environ. Toxicol. Chem., 34, 726-740.

MIAO A.J., W.X. WANG et P. JUNEAU (2005). Comparison of $\mathrm{Cd}, \mathrm{Cu}$, and $\mathrm{Zn}$ toxic effects on four marine phytoplankton by pulse-amplitude-modulated fluorometry. Environ. Toxicol. Chem., 24, 2603-2611.

MIGEON A., D. BLAUDEZ, O. WILKINS, B. MONTANINI, M.M. CAMPBELL, P. RICHAUD, S. THOMINE et M. CHALOT (2010). Genome-wide analysis of plant metal transporters, with an emphasis on poplar. Cell. Mol. Life Sci., 67, 3763-3784.

MOFFETT J.W. et J. HO (1996). Oxidation of cobalt and manganese in seawater via a common microbially catalyzed pathway. Geochim. Cosmochim. Acta, 60, 3415-3424.

MOREL F.M.M. (1983). Principles of Aquatic Chemistry. John Wiley \& Sons, Somerset, NJ, États-Unis, 446 p.

MOREL F.M.M. (2008). The co-evolution of phytoplankton and trace element cycles in the oceans. Geobiology, 6, 318324.

MORIN S., VIVAS-NOGUES M., T.T. DUONG, A. BOUdOU, M. COSTE et F. DELMAS (2007). Dynamics of benthic diaton colonization in a cadmium/ zinc-polluted river (Riou-Mort, France). Fund. Appl. Limnol., 168, 179-187.

MUELLER K.K., S. LOFTS, C. FORTIN et P.G.C. CAMPBELL (2012). Trace metal speciation predictions in natural aquatic systems: incorporation of dissolved organic matter (DOM) spectroscopic quality. Environ. Chem., 9, 356-368.

MURRAY K.J., S.M. WEBB, J.R. BARGAR et B.M. TEBO (2007). Indirect oxidation of $\mathrm{Co}(\mathrm{II})$ in the presence of the marine $\mathrm{Mn}(\mathrm{II})$-oxidizing bacterium Bacillus sp. strain SG-1. Appl. Environ. Microb., 73, 6905-6909.
NAITO K., M. SUZUKI, S. MITO, H. HASEGAWA, I. IMAI, Y. SOHRIN et M. MATSUI (2001). The pursuit of siderophore secreted by marine phytoplankton Rhodomonas ovalis. Anal. Sci., 17, 1817-1819.

NAITO K., M. SUZUKI, M. MATSUI et I. IMAI (2004). Secretion of iron-complexing ligands from Closterium aciculare (Charophyceae, Chlorophyta) under irondeficient conditions. Phycologia, 43, 632-634.

NASSIRI Y., J. WÉRY, J.L. MANSOT et T. GINSBURGERVOGEL (1997). Cadmium bioaccumulation in Tetraselmis suecica: An electron energy loss spectroscopy (EELS) study. Arch. Environ, Contam. Toxicol., 33, 156-161.

NEVO Y. et N. NELSON (2006). The NRAMP family of metal-ion transporters. BBA - Mol. Cell Res., 1763, 609620.

PAGE M.D., J. KROPAT, P.P. HAMEL et S.S. MERCHANT (2009). Two Chlamydomonas CTR copper transporters with a novel Cys-Met motif are localized to the plasma membrane and function in copper assimilation. The Plant Cell, 21, 928-943.

PALENIK B., J. GRIMWOOD, A. AERTS, P. ROUZE, A. SALAMOV, N. PUTNAM, C. DUPONT, R. JORGENSEN, E. DERELLE, S. ROMBAUTS, K.M. ZHOU, R. OTILLAR, S.S. MERCHANT, S. PODELL, T. GAASTERLAND, C. NAPOLI, K. GENDLER, A. MANUELL, V. TAI, O. VALLON, G. PIGANEAU, S. JANCEK, M. HEIJDE, K. JABBARI, C. BOWLER, M. LOHR, S. ROBBENS, G. WERNER, I. DUBCHAK, G.J. PAZOUR, Q.H. REN, I. PAULSEN, C. DELWICHE, J. SCHMUTZ, D. ROKHSAR, Y. VAN DE PEER, H. MOREAU et I.V. GRIGORIEV (2007). The tiny eukaryote Ostreococcus provides genomic insights into the paradox of plankton speciation. Proc. Natl. Acad. Sci. (USA), 104, 7705-7710.

PALMGREN M.G. (2001). Plant plasma membrane $\mathrm{H}^{+}-$ ATPases: Powerhouses for nutrient uptake. Ann. Rev. Plant Physiol., 52, 817-845.

PANKOW J.F. et J.J. MORGAN (1981). Kinetics for the aquatic environment. Part II. Environ. Sci. Technol., 15, 1306-1313.

PAQUET N., M. LAVOIE, F. MALONEY, J. DUVAL, P.G.C. CAMPBELL et C. FORTIN (2015). Cadmium accumulation and toxicity in the unicellular alga Pseudokirchneriella subcapitata: Influence of metal-binding exudates and exposure time. Environ. Toxicol. Chem., 34, 1524-1532. 
PAQUIN P.R., D.M. DI TORO, R.C. SANTORE, D. TRIVEDI et K.B. WU (1999). A biotic ligand model of the acute toxicity of metals. III. Application to fish and Daphnia exposure to silver. Dans: Integrated approach to assessing the bioavailiability and toxicity of metals in surface waters and sediments. EPA Science Advisory Board, Office of Research and Development, Washington, DC, ÉtatsUnis, pp. 3-102.

PAQUIN P.R., J.W. GORSUCH, S. APTE, G.E. BATLEY, K.C. BOWLES, P.G.C. CAMPBELL, C.G. DELOS, D.M. DI TORO, R.L. DWYER, F. GALVEZ, R.W. GENSEMER, G.G. GOSS, C. HOGSTRAND, C.R. JANSSEN, J.C. MCGEER, R.B. NADDY, R.C. PLAYLE, R.C. SANTORE, U. SCHNEIDER, W.A. STUBBLEFIELD, C.M. WOOD et K.B. WU (2002a). The biotic ligand model: A historical overview. Comp. Biochem. Physiol. C, 133, 3-35.

PAQUIN P.R., V. ZOTAY, R.P. WINFIELD, K.B. WU, R. MATHEW, R.C. SANTORE et D.M. DI TORO (2002b). Extension of the biotic ligand model of acute toxicity to a physiologically-based model of the survival time of rainbow trout (Oncorhynchus mykiss) exposed to silver. Comp. Biochem. Physiol. C, 133, 305-343.

PHINNEY J.T. et K.W. BRULAND (1994). Uptake of lipophllic organic $\mathrm{Cu}, \mathrm{Cd}$, and $\mathrm{Pb}$ complexes in the coastal diatom Thalassiosira weissflogii. Environ. Sci. Technol., 28, 1781-1790.

PINHEIRO J.P. et H.P. VAN LEEUWEN (2001). Metal speciation dynamics and bioavailability. 2. Radial diffusion effects in the microorganism range. Environ. Sci. Technol., 35, 894-900.

PINTO E., T.C.S. SIGAUD-KUTNER, M.A.S. LEITAO, O.K. OKAMOTO, D. MORSE et P. COLEPICOLO (2003). Heavy metal-induced oxidative stress in algae. J. Phycol., 39, 1008-1018.

QIAN J., H.B. XUE, L. SIGG et A. ALBRECHT (1998). Complexation of cobalt by natural ligands in freshwater. Environ. Sci. Technol., 32, 2043-2050.

REA P.A., O.K. VATAMANIUK et D.J. RIGDEN (2004). Weeds, worms, and more. Papain's long-lost cousin, phytochelatin synthase. Plant Physiol., 136, 2463-2474.

REID R.J. (2001). Mechanisms of micronutrient uptake in plants. Aust. J. Plant Physiol., 28, 659-666.
RICHARDSON L.L., C. AGUILAR et K.H. NEALSON (1988). Manganese oxidation in $\mathrm{pH}$ and $\mathrm{O}_{2}$ microenvironments produced by phytoplankton. Limnol. Oceanogr., 33, 352-363.

RICHARDSON L.L. et K.D. STOLZENBACH (1995). Phytoplankton cell-size and the development of microenvironments. FEMS Microbiol. Ecol., 16, 185-191.

ROSAKIS A. et W. KÖSTER (2004). Transition metal transport in the green microalga Chlamydomonas reinhardtii - Genomic sequence analysis. Res. Microbiol., $155,201-210$.

ROSAKIS A. et W. KÖSTER (2005). Divalent metal transport in the green microalga Chlamydomonas reinhardtii is mediated by a protein similar to prokaryotic NRAMP homologues. BioMetals, 18, 107-120.

ROSKO J.J. et J.W. RACHLIN (1977). The effect of cadmium, copper, mercury, zinc and lead on cell division, growth, and chlorophyll-a content of the chlorophyte Chlorella vulgaris. Bull. Torrey Bot. Club, 104, 226-233.

RUIZ F.A., N. MARCHESINI, M. SEUFFERHELD, GOVINDJEE et R. DOCAMPO (2001). The polyphosphate bodies of Chlamydomonas reinhardtii possess a proton-pumping pyrophosphatase and are similar to acidocalcisomes. J. Biol. Chem., 276, 46196-46203.

SAITO M.A., D.M. SIGMAN et F.M.M. MOREL (2003). The bioinorganic chemistry of the ancient ocean: The co-evolution of cyanobacterial metal requirements and biogeochemical cycles at the Archean-Proterozoic boundary? Inorg. Chim. Acta, 356, 308-318.

SHARMA V.K. et F.J. MILLERO (1988). Oxidation of copper(I) in sea water. Environ. Sci. Technol., 22, 768-771.

SHELDON J.R. et D.E. HEINRICHS (2015). Recent developments in understanding the iron acquisition strategies of gram positive pathogens. FEMS Microbiol. Rev., 39, 592-630.

SIGG L., P. BEHRA et W. STUMM (2006a). Chimie des milieux aquatiques : chimie des eaux naturelles et des interfaces dans l'environnement. Dunod, Paris, France, 564 p. 
SIGG L., F. BLACK, J. BUFFLE, J. CAO, R. CLEVEN, W. DAVISON, J. GALCERAN, P. GUNKEL, E. KALIS, D. KISTLER, M. MARTIN, S. NOËL, Y. NUR, N. ODZAK, J. PUY, W. VAN RIEMSDIJK, E. TEMMINGHOFF, M.L. TERCIER-WAEBER, S. TOEPPERWIEN, R.M. TOWN, E. UNSWORTH, K.W. WARNKEN, L. WENG, H. XUE et H. ZHANG (2006b). Comparison of analytical techniques for dynamic trace metal speciation in natural freshwaters. Environ. Sci. Technol., 40, 1934-1941.

SIMON D.F., T.A. DAVIS, M.L. TERCIER-WAEBER, R. ENGLAND et K.J. WILKINSON (2011). In situ evaluation of cadmium biomarkers in green algae. Environ. Pollut., 159, 2630-2636.

SKOWRONSKI T., B. PAWLIK et M. JAKUBOWSKI (1988). Reduction of cadmium toxicity to green microalga Stichococcus bacillaris by manganese. Bull. Environ. Contam. Toxicol., 41, 915-920.

SLAVEYKOVA V.I. et K.J. WILKINSON (2002). Physicochemical aspects of lead bioaccumulation by Chlorella vulgaris. Environ. Sci. Technol., 36, 969-975.

SLAVEYKOVA V.I. et K.J. WILKINSON (2005). Predicting the bioavailability of metals and metal complexes: Critical review of the biotic ligand model. Environ. Chem., 2, 9-24.

STAUBER J.L. et T.M. FLORENCE (1987). Mechanism of toxicity of ionic copper and copper complexes to algae. Mar. Biol., 94, 511-519.

STUMM W. et J.J. MORGAN (1996). Aquatic Chemistry Chemical Equilibria and Rates in Natural Waters. Third edition. John Wiley \& Sons, États-Unis, 1022 p.

SUN J., C. TANG, P. WU, C. LIU et R. ZHANG (2013). Migration of $\mathrm{Cu}, \mathrm{Zn}, \mathrm{Cd}$ and As in epikarst water affected by acid mine drainage at a coalfield basin, Xingren, Southwest China. Environ. Earth Sci., 69, 2623-2632.

SUNDA W. (2012). Feedback interactions between trace metal nutrients and phytoplankton in the ocean. Front. Microbiol., 3, 204.

SUNDA W.G. et R.R.L. GUILLARD (1976). The relationship between cupric ion activity and the toxicity of copper to phytoplankton. J. Mar. Res., 34, 511-529.

SUNDA W.G. et S.A. HUNTSMAN (1986). Relationships among growth rate, cellular manganese concentrations and manganese transport kinetics in estuarine and oceanic species of the diatom Thalassiosira. J. Phycol., 22, 259-270.
SUNDA W.G. et S.A. HUNTSMAN (1988). Effect of sunlight on redox cycles of manganese in the southwestern Sargasso Sea. Deep-Sea Res., 35, 1297-1317.

SUNDA W.G. et S.A. HUNTSMAN (1992). Feedback interactions between zinc and phytoplankton in seawater. Limnol. Oceanogr., 37, 25-40.

SUNDA W.G. et S.A. HUNTSMAN (1995a). Iron uptake and growth limitation in oceanic and coastal phytoplankton. Mar. Chem., 50, 189-206.

SUNDA W.G. et S.A. HUNTSMAN (1995b). Regulation of copper concentration in the oceanic nutricline by phytoplankton uptake and regeneration cycles. Limnol. Oceanogr., 40, 132-137.

SUNDA W.G. et S.A. HUNTSMAN (1996). Antagonisms between cadmium and zinc toxicity and manganese limitation in a coastal diatom. Limnol. Oceanogr., 41, 373387.

SUNDA W.G. et S.A. HUNTSMAN (1998a). Control of Cd concentrations in a coastal diatom by interactions among free ionic $\mathrm{Cd}, \mathrm{Zn}$, and $\mathrm{Mn}$ in seawater. Environ. Sci. Technol., 32, 2961-2968.

SUNDA W.G. et S.A. HUNTSMAN (1998b). Interactions among $\mathrm{Cu}^{2+}, \mathrm{Zn}^{2+}$, and $\mathrm{Mn}^{2+}$ in controlling cellular $\mathrm{Mn}$, $\mathrm{Zn}$, and growth rate in the coastal alga Chlamydomonas. Limnol. Oceanogr., 43, 1055-1064.

SUNDA W.G. et S.A. HUNTSMAN (1998c). Processes regulating cellular metal accumulation and physiological effects: Phytoplankton as model systems. Sci. Total Environ., 219, 165-181.

SUNDA W.G. et S.A. HUNTSMAN (2000). Effect of Zn, $\mathrm{Mn}$, and $\mathrm{Fe}$ on $\mathrm{Cd}$ accumulation in phytoplankton: Implications for oceanic Cd cycling. Limnol. Oceanogr., 45, 1501-1516.

SZIVAK I., R. BEHRA et L. SIGG (2009). Metal-induced reactive oxygen species production in Chlamydomonas reinhardtii (Chlorophyceae). J. Phycol., 45, 427-435.

TEBO B.M. (1998). Mn(II) oxidation in marine environments is likely bacterial. Comment on "Comment on 'Oxidation of cobalt and manganese in seawater via a common microbially catalyzed pathway' by J.W. Moffett and J. Ho". Geochim. Cosmochim. Acta, 62, 357-358. 
TEMPLETON D.M., F. ARIESE, R. CORNELIS, L.G. DANIELSSON, H. MUNTAU, H.P. VAN LEEUWEN et R. LOBINSKI (2000). Guidelines for terms related to chemical speciation and fractionation of elements. Definitions, structural aspects, and methodological approaches (IUPAC recommendations 2000). Pure Appl. Chem., 72, 1453-1470.

TERCIER-WAEBER M.-L., F. CONFALONIERI, G. RICCARDI, A. SINA, S. NOËLA, J. BUFFLE et F. GRAZIOTTIN (2005). Multi physical-chemical profiler for real-time in situ monitoring of trace metal speciation and master variables: Development, validation and field applications. Mar. Chem., 97, 216-235.

TERCIER WAEBER M.-L., S. STOLL et V. SLAVEYKOVA (2012). Trace metal behavior in surface waters: Emphasis on dynamic speciation, sorption processes and bioavailability. Arch. Sci., 65, 119-142.

THOMINE S., R. WANG, J.M. WARD, N.M. CRAWFORD et J.I. SCHROEDER (2000). Cadmium and iron transport by members of a plant metal transporter family in Arabidopsis with homology to NRAMP genes. Proc. Natl. Acad. Sci. (USA), 97, 4991-4996.

TIPPING E. (1998). Humic ion-binding model VI: An improved description of the interactions of protons and metal ions with humic substances. Aquat. Geochem., 4, $3-48$.

TIPPING E. et S. LOFTS (2015). Testing WHAM-FTOX with laboratory toxicity data for mixtures of metals $(\mathrm{Cu}$, $\mathrm{Zn}, \mathrm{Cd}, \mathrm{Ag}, \mathrm{Pb})$. Environ. Toxicol. Chem., 34, 788-798.

TÖPPERWIEN S., R. BEHRA et L. SIGG (2007a). Competition among zinc, manganese, and cadmium uptake in the freshwater alga Scenedesmus vacuolatus. Environ. Toxicol. Chem., 26, 483-490.

TÖPPERWIEN S., H. XUE, R. BEHRA et L. SIGG (2007b). Cadmium accumulation in Scenedesmus vacuolatus under freshwater conditions. Environ. Sci. Technol., 41, 53835388.

TORRICELLI E., G. GORBI, B. PAWLIK-SKOWRONSKA, L.S. DI TOPPI et M.G. CORRADI (2004). Cadmium tolerance, cysteine and thiol peptide levels in wild type and chromium-tolerant strains of Scenedesmus acutus (Chlorophyceae). Aquat. Toxicol., 68, 315-323.
TRICK C.G., R.J. ANDERSEN, A. GILLAM et P.J. HARRISON (1983a). Prorocentrin: An extracellular siderophore produced by the marine dinoflagellate Prorocentrum minimum. Science, 219, 306-308.

TRICK C.G., R.J. ANDERSEN, N.M. PRICE, A. GILLAM et P.J. HARRISON (1983b). Examination of hydroxamatesiderophore production by neritic eukaryotic marine phytoplankton. Mar. Biol., 75, 9-17.

TUKAJ Z., A. BASCIK-REMISIEWICZ, T. SKOWRONSKI et C. TUKAJ (2007). Cadmium effect on the growth, photosynthesis, ultrastructure and phytochelatin content of green microalga Scenedesmus armatus: A study at low and elevated $\mathrm{CO}_{2}$ concentration. Environ. Exper. Bot., 60, 291-299.

TWISS M.R., S.P. GOUVÊA, R.A. BOURBONNIERE, R.M.L. MCKAY et S.W. WILHELM (2005). Field investigations of trace metal effects on lake Erie phytoplankton productivity. J. Great Lakes Res., 31, 168179.

UNITED STATES ENVIRONMENTAL PROTECTION AGENCY (US EPA) (2007). Aquatic life ambiant freshwater quality criteria - Copper. Office of Water, Office of Science and Technology, Washington, DC, États-Unis, 204 p.

VON LANGEN P.J., K.S. JOHNSON, K.H. COALE et V.A. ELROD (1997). Oxidation kinetics of manganese(II) in sea water at nanomolar concentrations. Geochim. Cosmochim. Acta, 61, 4945-4954.

VOUTSINAS G., F.E. ZARANI et A. KAPPAS (1997). The effect of environmental aneuploidy-inducing agents on the microtubule architecture of mitotic meristematic root cells in Hordeum vulgare. Cell Biol. Int., 21, 411-418.

WEGER H.G. et G.S. ESPIE (2000). Ferric reduction by iron-limited Chlamydomonas cells interacts with both photosynthesis and respiration. Planta, 210, 775-781.

WHITFIELD M. et D.R. TURNER (1979). Critical assessment of the relationship between biological thermodynamic and electrochemical availability. Dans : Chemical Modeling in Aqueous Systems. EVERETT J.A (Éditeur), American Chemical Society Symposium Series, Vol. 93, Chap. 29, pp. 657-680. 
WILKINSON K.J. et J. BUFFLE (2004). Critical evaluation of physicochemical parameters and processes for modelling the biological uptake of trace metals in environmental (aquatic) systems. Dans : Physicochemical Kinetics and Transport at Biointerfaces. LEEUWEN H.P.V. et W. KÖSTER (Éditeurs), IUPAC Series on Analytical and Physical Chemistry of Environmental Systems, Vol. 9, John Wiley \& Sons, Chichester, Royaume-Uni, Chap. 10.

WILLIAMS R.J.P. (2002). The fundamental nature of life as a chemical system: The part played by inorganic elements. J. Inorg. Biochem., 88, 241-250.

WORMS I.A.M. et K.J. WILKINSON (2007). Ni uptake by a green alga. 2. Validation of equilibrium models for competition effects. Environ. Sci. Technol., 41, 4264-4270.

XUE H. et L. SIGG (1993). Free cupric ion concentration and $\mathrm{Cu}(\mathrm{II})$ speciation in a eutrophic lake. Limnol. Oceanogr., $38,1200-1213$.

XUE H. et L. SIGG (1994). Zinc speciation in lake waters and its determination by ligand exchange with EDTA and differential pulse anodic stripping voltammetry. Anal. Chim. Acta, 284, 505-515.

XUE H. et L. SIGG (1998). Cadmium speciation and complexation by natural organic ligands in fresh water. Anal. Chim. Acta, 363, 249-259.
XUE H., D. KISTLER et L. SIGG (1995). Competition of copper and zinc for strong ligands in a eutrophic lake. Limnol. Oceanogr., 40, 1142-1152.

XUE H., A. OESTREICH, D. KISTLER et L. SIGG (1996). Free cupric ion concentrations and $\mathrm{Cu}$ complexation in selected Swiss lakes and rivers. Aquat. Sci., 58, 69-87.

XUE H. et W.G. SUNDA (1997). Comparison of $\left[\mathrm{Cu}^{2+}\right]$ measurements in lake water determined by ligand exchange and cathodic stripping voltammetry and by ion-selective electrode. Environ. Sci. Technol., 31, 1902-1909.

XUE X., C.M. COLLINS et H.G. WEGER (1998). The energetics of extracellular $\mathrm{Fe}$ (III) reduction by iron-limited Chlamydomonas reinhardtii (Chlorophyta). J. Phycol., 34, 939-944.

YRUELA I. (2013). Transition metals in plant photosynthesis. Metallomics, 5, 1090-1109.

ZHAO C.-M., P.G.C. CAMPBELL et K.J. WILKINSON (2016). When are metal complexes bioavailable? Environ. Chem., 13 (sous presse). DOI: 10.1071/EN15205 